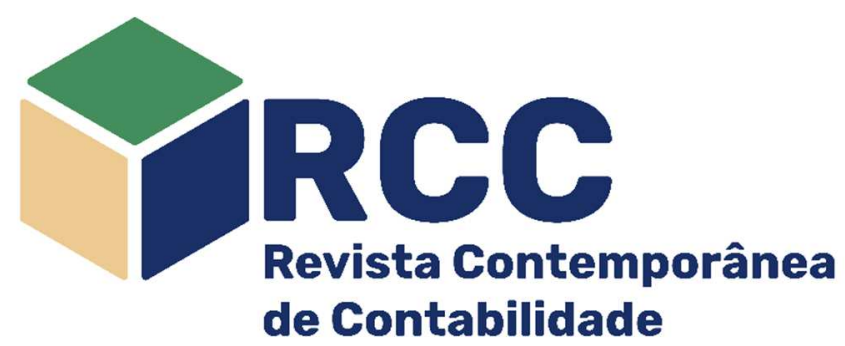

\title{
Qualidade da auditoria e assimetria informacional: uma análise no período pré e pós-adoção às normas internacionais de contabilidade
}

Audit quality and informational asymmetry: an analysis in the period before and after adoption of the international accounting standards

Calidad de la auditoría y asimetría informacional: un análisis en el período pre y post-adopción a las normas internacionales de contabilidad

Térsio Arcúrio Júnior*

Doutorando no Programa de Pós-graduação em Ciências Contábeis da Universidade de Brasília - PPGCont (UnB) Especialista em Regulação de Serviços Públicos de Telecomunicações, Brasília/DF, Brasil tersioarcurio@hotmail.com https://orcid.org/0000-0002-7210-3266 (i)
Rodrigo de Souza Gonçalves Doutor em Ciências Contábeis pelo Programa Multiinstitucional e Inter-regional de Ciências Contábeis (UnB/UFPB/UFRN) Professor Associado da Faculdade de Economia Administração e Contabilidade (UnB), Brasília/DF, Brasil rgoncalves@unb.br

https://orcid.org/0000-0003-3768-2968 (c)

Endereço do contato principal para correspondência* SQNW Qd, 109 BL A, Ap. 619, Setor Noroeste - CEP: 70686405 - Brasília/DF - Brasil

\section{Resumo}

O estudo objetiva investigar quais elementos da qualidade da auditoria (QA) contribuem para a redução da assimetria de informação ( $\mathrm{Al}$ ) nas empresas listadas da $\mathrm{B}^{3}$, no período pré e pós-adoção das IFRS. Foram estimadas regressões com dados em painel para testar a relação entre a $\mathrm{Al}$ e a QA em 82 empresas no período de 2003 a 2016. Os principais resultados são: existe relação significante e negativa entre elementos de QA (BIG4, TA, ESP e CA) e a Al; existe relação significante e negativa entre as variáveis de controle (COB, INT, FLOAT e NM) e a Al e; existe maior relevância da QA na redução da Al no período pós-adoção. O estudo pode contribuir: ao evidenciar os atributos de QA associados à qualidade informacional; para que reguladores e normatizadores tenham mais subsídios informacionais e; ao possibilitar a identificação, pelos investidores, de características de empresas com maior qualidade informacional.

Palavras-chave: Qualidade informacional; Qualidade da auditoria; Assimetria de informação; Convergência internacional

\begin{abstract}
This study investigates which elements of audit quality (AQ) contribute to the reduction of information asymmetry $(\mathrm{Al})$ in $\mathrm{B}^{3}$ listed companies in the period before and after IFRS adoption. Regressions with panel data were estimated to test the relationship between IA and AQ in 82 companies between 2003 and 2016. The main results are: there is a significant and negative relationship between AQ elements (BIG4, TA, ESP and $C A$ ) and IA; there is a significant and negative relationship between the control variables (COB, INT, FLOAT and $N M$ ) in relation to IA and; there is a higher relevance of the $A Q$ in reducing the $A I$ in the IFRS post-adoption period. The study can contribute: showing which attributes related to the $A Q$ are associated with the information quality; providing the capital market and accounting practices regulators informational subsidies and; helping investors to improve the identification of companies' characteristics with higher information quality. Keywords: Informational quality; Audit quality; Information asymmetry; International convergence
\end{abstract}

\section{Resumen}

El estudio objetiva investigar elementos de la calidad de la auditoria (CA) contribuyen para la reducción de la asimetría de información (Al) en las empresas listadas en la $\mathrm{B}^{3}$, en el período pre y post-adopción de las IFRS. 
Se estimaron regresiones para testar la relación entre la Al y la QA en 82 empresas (2003 hasta el 2016). Los principales resultados son: existe relación significante y negativa entre elementos de la CA (BIG4, TA, ESP y $\mathrm{CA}$ ) y la Al; existe relación significante y negativa entre las variables de control (COB, INT, FLOAT y NM) y AI y; existe mayor relevancia de la $\mathrm{CA}$ en la reducción de la Al en el período post-adopción. El estudio puede contribuir: destacando los atributos de QA asociados con la calidad de la información (Cl); para que los reguladores y normatizadores tengan más subsidios informativos y; posibilita que los inversores identifiquen las empresas con mayor $\mathrm{Cl}$.

Palabras-clave: Calidad de información; Calidad de la auditoria; Asimetría de información; Convergencia internacional

\section{Introdução}

A convergência às normas internacionais de contabilidade busca alcançar maior qualidade da divulgação da informação, melhorar o processo comparativo, bem como a precificação dos ativos, por meio do reporte sob um mesmo padrão entre diversas empresas (ASHNUGH, 2001; SALTER, ROBERTS; KANTOR, 1996; SANTOS et al., 2011; YIP; YOUNG, 2012). Barth, Landsman e Lang (2008) mencionam que para atingir o objetivo de promover a qualidade da informação, a convergência busca limitar o uso de alternativas contábeis e fornecer informações adequadas para a tomada de decisão.

Desse modo, entende-se que a qualidade da informação está relacionada à relevância de sua influência na decisão do usuário da informação contábil, sendo associada ao poder informativo sobre o desempenho financeiro da empresa (DECHOW; GE; SCHRAND, 2010), ou seja: informações contábeis mais transparentes (COELHO; NIYAMA; RODRIGUES, 2011), que representem fidedignamente a entidade reportada e, consequentemente, informações com menor suavização e gerenciamento de resultados, mais tempestivas e maior associação dos números contábeis ao valor/retorno das ações (EWERT; WAGENHOFER, 2005; BARTH; LANDSMAN; LANG, 2008; CHRISTENSEN et al., 2015).

Nota-se também que, ante a importância da qualidade da informação contábil, sua divulgação tem se destacado como mecanismo de disseminação, onde a maior qualidade da divulgação contábil tem sido utilizada para suprir as necessidades dos investidores. No entanto, somente uma maior qualidade da divulgação parece não resolver todos os problemas dos investidores. A assimetria de informação, por exemplo, tem sido um problema que a divulgação contábil, apesar de ser referenciada como medida para sua redução (LEV, 1988; WELKER, 1995; VERRECCHIA, 2001; BIDDLE; HILARY, 2006), não consegue eliminála (BEATTY; HARRIS, 1998).

Nesse aspecto, a fim de propiciar uma maior simetria entre os investidores e um ambiente de negociação mais justo, o papel exercido pela auditoria independente merece destaque, dado que esta tem por objetivo aumentar o grau de confiança das informações contábeis, mediante opinião em relação à conformidade na elaboração das demonstrações contábeis, em todos os aspectos relevantes (NBC TA 200). À medida que isso ocorre (asseguração das informações contábeis) há uma sinalização de que tais informações estão livres de distorções relevantes (FAFATAS, 2010), o que por sua vez, promove maior segurança ao investidor externo acerca da qualidade das demonstrações contábeis (HU, 2015).

Nesse cenário, a auditoria atua como intermediária das informações contábeis, agindo no sentido de dar maior qualidade à informação e, consequentemente, de minimizar a assimetria informacional entre o agente e o principal (HEALY; PALEPU, 2001). Diante disso, espera-se que quanto maior for a qualidade da auditoria, melhor será o resultado de seu trabalho, isto é, maior será a qualidade da informação contábil divulgada.

Com isso, tem-se a importância da existência das normas, quer de contabilidade ou de auditoria, e especificamente dos atributos que podem favorecer uma maior qualidade da auditoria, tais como: tamanho, tempo de relacionamento com o cliente, especialização em determinados setores, honorários da auditoria e distância entre a data do relatório de auditoria e a publicação das demonstrações contábeis (FRANCIS, 2011; PAULO, CAVALCANTE; PAULO, 2013; KNECHEL et al.; 2013; DANTAS; MEDEIROS, 2015; HU, 2015; SALEHI; MORADI; PAIYDARMANESH, 2017), no sentido de promoverem a indução de informações oportunas e relevantes aos usuários da informação contábil, que visem, dentre outros fatores, a redução da assimetria informacional.

Diante do exposto, notadamente quanto ao elo entre a assimetria de informação e o papel auditoria, tem-se o seguinte questionamento: qual a influência da qualidade da auditoria na assimetria de informação nas empresas listadas da $\mathrm{B}^{3}$, no período pré e pós-adoção das normas internacionais de contabilidade?

O objetivo desse estudo é investigar quais elementos da qualidade da auditoria contribuem para a redução da assimetria de informação, considerando os períodos de diferentes padrões contábeis (pré e pósadoção das normas internacionais de contabilidade).

$\mathrm{Na}$ literatura acadêmica há diversos estudos a respeito da assimetria de informação (LEV, 1988, BHATTACHARYA; SPEIGEL, 1991; DIAMOND; VERRECCHIA, 1991; WELKER, 1995; FLEMING, 1997; BEATTY; HARRIS, 1998; HEALY; PALEPU, 2001; BIDDLE; HILARY, 2006; ATTIG et al., 2006; WITTENBERGMOERMAN, 2008; BHAT; JAYARAMAN, 2010; GIRÃO; MACHADO, 2013; RODRIGUES; GALDI, 2017). Porém, apesar de parecer existir uma relação negativa com auditoria independente, há uma lacuna quanto aos estudos que busquem analisar a relação entre a assimetria de informação e os atributos de qualidade da 
auditoria, considerando a adoção das normas internacionais de contabilidade, especialmente sob a ótica comparativa (antes e após à sua adoção).

Ao analisar dessa forma, o estudo é relevante à medida que há uma expectativa que a partir da adoção às normas internacionais espera-se haver um ganho quanto à maior qualidade informacional, e consequentemente, deveria haver diminuição na assimetria informacional. Contudo, a maior discricionariedade no reconhecimento, mensuração e evidenciação das IFRS torna este cenário desafiador, dado o ambiente propício ao gerenciamento de resultados, realçando ainda mais o papel exercido pelos auditores dada a maior complexidade das normas internacionais e o ambiente de baixa proteção legal aos investidores (KIM; LIU; ZHENG, 2012; MARTÍNEZ-FERRERO; VILLARÓN-PERAMATO; GARCÍASANCHEZ, 2017).

\section{Revisão de Literatura}

\subsection{A adoção das IFRS, a melhoria da qualidade da informação e a redução da assimetria de informação}

A adoção das IFRS objetiva melhorar a qualidade da informação contábil (BARTH; LANDSMAN; LANG, 2008), o que sugere que se o seu objetivo for atingido, haveria uma redução da assimetria de informações (IATRIDIS, 2010).

Desse modo, a qualidade da informação contábil, com a adoção das IFRS, seria atingida com o aprimoramento da comparabilidade de informações (ASHNUGH, 2001; SALTER, ROBERTS; KANTOR, 1996; SANTOS et al., 2011; YIP; YOUNG, 2012), aumento do poder informativo sobre o desempenho financeiro da empresa (DECHOW; GE; SCHRAND, 2010), maior transparência (COELHO, NIYAMA; RODRIGUES, 2011), redução no gerenciamento de resultado (BARTH; LANDSMAN; LANG, 2008; IATRIDIS, 2010), e informações mais tempestivas e maior associação dos números contábeis ao valor/retorno das ações (EWERT; WAGENHOFER; 2005; BATH, LANDSMAN; LANG 2008; IATRIDIS, 2010; PAULO; CAVALCANTE; MELO, 2012).

De modo geral, há evidências de que a adoção das IFRS reduziu o nível de suavização e gerenciamento dos resultados (BARTH, LANDSMAN; LANG, 2008; IATRIDIS, 2010; CHEN et al., 2010; BOMFIM et al., 2016; PIRES DA SILVA et al., 2017), e, portanto, para latridis (2010), esse contexto sugerese uma menor assimetria de informação.

Para Daske et al. (2008) que analisaram a introdução das IFRS em 26 países, constatou-se, após sua adoção, a existência de maior liquidez do mercado, redução no custo de capital e aumento nas avaliações dos valores das empresas, contudo, tais resultados foram observados em países que incentivam a transparência e possuem um maior enforcement.

Rezende, Almeida e Lemes (2015) identificaram que a adoção obrigatória das IFRS reduziu a assimetria de informação somente em empresas classificadas como Blue Chips, enquanto Hao, Sun e Yin (2019) levantam evidências de maior agressividade nos accruals e menor tempestividade no reconhecimento de perdas em locais de menor desenvolvimento do ambiente legal. Para Zeff (2007, p. 291), por exemplo, fatores culturais como (a) cultura financeira e de negócios, (b) cultura contábil, (c) cultura de auditoria e (d) cultura regulatória, se apresentariam mais que desafios, mas como obstáculos que "impedem ou interferem na genuína promoção da comparabilidade em todo o mundo".

Portanto, a melhoria objetivada pela adoção das IFRS é sensível a fatores como: ambiente de negócios, ambiente regulatório, características das organizações, questões culturais, que podem dificultar, senão impedir que o objetivo de melhoria da informação.

Nesse sentido, embora o objetivo da IFRS seja aumentar a qualidade da informação e com isso reduzir a assimetria de informações, constatam-se críticas em relação à sua adoção, tais como: diversos países adotaram as IFRS, porém existem diferenças de aplicabilidade da norma, problemas de linguagem e de enforcement entre eles (NOBES, 2013); as normas não foram elaboradas visando à comparabilidade almejada pela sociedade (DUROCHER; GENDRON, 2011; ZHANG; AMDREW, 2010).

Diante dos mais variados desafios que a convergência às IFRS impõe aos elaboradores e usuários da informação contábil, o papel exercido pela auditoria independente, especialmente aquela de maior qualidade, pode ser um relevante mecanismo nesse cenário por meio da exigência de que as normas sejam aplicadas à luz da representação fidedigna e de relevância, de forma contribuir para a melhoria da informação contábil e, consequentemente, da redução da assimetria.

\subsection{O papel da qualidade da auditoria na redução da assimetria de informação}

Um ambiente de informação assimétrica no âmbito do mercado de capitais diz respeito quando uma das partes envolvidas em uma transação tem mais e/ou melhores informações para tomar decisões em relação aos demais (BEAVER, 1968). Beatty e Harris (1998) e Rodrigues e Galdi (2017) afirmam que a assimetria de informações é derivada do oportunismo de uma das partes envolvidas, quando um ou mais interessados tem a oportunidade de promover seu próprio interesse em virtude da diferença na quantidade 
de informações entre os agentes envolvidos, ou ainda, quando uma das partes possui um conjunto mais completo de informações.

É nesse cenário que a informação contábil constitui-se em um dos elementos para promoção de um ambiente de negócios mais justo, possibilitando a redução da assimetria existente entre o usuário do capital e seu fornecedor (HEALY; PALEPU, 2001), auxiliando o segundo na avaliação dos cuidados que o agente dispõe para maximização de sua riqueza. Para tanto, Leibler (2003) e Barth, Landsman e Lang (2008) afirmam que a informação contábil sustentada em princípios contribui no fornecimento de uma informação mais alinhada à representação fidedigna do evento econômico, reduzindo o viés normativo e contribuindo para a diminuição da assimetria (COSENZA, 2003).

Por outro lado, em razão de possuírem intrinsicamente maior subjetividade na escolha de práticas contábeis, tais informações podem ser manipuladas com o fim de: (i) evitar a divulgação de perdas (REIS; LAMOUNIER; BRESSAN, 2015); (ii) minimizar a volatilidade dos resultados (MYERS; MYERS; SKINNER, 2007); (iii) melhorar a remuneração dos administradores (DECHOW; SKINNER, 2000); (iv) influenciar o mercado acionário, facilitar a obtenção de empréstimos e atender à fiscalização ou monitoramento de agências reguladoras (HEALY; WAHLEN, 1999) e; (v) captar recursos por meio de oferta de ações no mercado de capitais (DARROUGH; RANGAN, 2005); fatores que podem aumentar o viés da informação contábil e com isso a assimetria informacional.

Nesse contexto, destaca-se o papel da auditoria de ser um agente que assegura a qualidade da informação, preparada pela administração e destinada ao usuário externo (HEALY; PALEPU, 2001), promovendo maior qualidade à informação contábil e um ambiente de maior segurança no processo decisório de comprar, manter ou vender os ativos financeiros de uma organização (SALEHI; MORADI; PAIYDARMANESH, 2017).

Para DeAngelo (1981), a auditoria pode contribuir para a redução da assimetria ao assegurar que as informações contábeis sejam divulgadas sem distorções, omissões ou vieses relevantes, isto é, fatores intrínsecos à qualidade da auditoria.

Sob a perspectiva conceitual, a qualidade da auditoria pode ser entendida como a probabilidade conjunta avaliada pelo mercado de que o auditor irá descobrir e reportar uma violação do sistema contábil (DeANGELO, 1981), sendo também identificada à medida que estiver inversamente relacionada às falhas quanto aos seus procedimentos (FRANCIS, 2004), ou seja, quanto maior a qualidade da auditoria, menor a probabilidade de falhas de auditoria.

Segundo Chadegani (2011), a qualidade da auditoria é perceptível à medida que esta impulsione a elaboração de demonstrações contábeis confiáveis, uma vez que a alta qualidade de auditoria estaria associada à produção de informações financeiras sem distorções, omissões ou vieses relevantes.

Para Becker et al. (1998), a qualidade da auditoria está relacionada à habilidade do auditor em reduzir ou restringir práticas contábeis questionáveis que contribuam para assimetria entre gestores, acionistas e demais usuários da informação contábil. Sendo assim, a partir dos objetivos da auditoria independente, o presente estudo apresenta a seguinte hipótese geral:

\section{$H_{1}$ : A qualidade da auditoria independente está associada negativamente à assimetria de informações, no período pré e pós-adoção das IFRS.}

Em que pese ser claro o papel que a auditoria deve realizar no ambiente de negócios, para Hu (2015) há dificuldade em alcançar um consenso sobre o que vem a ser qualidade de auditoria, e ainda, o modo em que ela pode ser observada. Dantas e Medeiros (2015) ressaltam que devido à dificuldade ou impossibilidade de se mensurar objetivamente a qualidade da auditoria, são utilizadas variáveis baseadas em informações quanto ao processo de auditoria, quanto ao mercado financeiro, bem como em relação as informações contábeis divulgadas.

Em razão disso, há diversos estudos que apresentam um conjunto de diferentes variáveis que buscam capturar e mensurar a qualidade da auditoria (FRC, 2008; FRANCIS, 2011; PAULO; CAVALCANTE; PAULO, 2013; KNECHEL et al. 2013; DANTAS; MEDEIROS, 2015; IASSB, 2014; HU, 2015), dentre elas tem-se: tamanho da empresa de auditoria, tempo de auditoria, especialização da auditoria, atraso na divulgação (Delay) e honorários de auditoria.

DeAngelo (1981) argumenta que o tamanho da empresa de auditoria pode ser mensurado a partir do número de clientes, sob o argumento de que quanto maior a empresa de auditoria, menor será a relação de dependência com o cliente, reduzindo a probabilidade de comportamento oportunista. Essa ideia é corroborada por Francis (2004), Almeida e Almeida (2009) e Francis e Yu (2009).

Assim, considerando a possível associação entre qualidade da auditoria e o tamanho da empresa, entende-se que quanto maior for a empresa de auditoria, maior será a qualidade do serviço prestado e melhor será a qualidade da informação contábil e, portanto, menor assimetria informacional, resultando na seguinte hipótese:

\section{$\mathrm{H}_{1.1}$ : $\mathrm{O}$ tamanho da empresa de auditoria está associado negativamente à assimetria de informações, no período pré e pós-adoção das IFRS.}

Quanto ao tempo de auditoria, Gavious (2007) entende que um maior tempo de auditoria tende a gerar interesses econômicos, relações pessoais e de lealdades, enfraquecendo a objetividade, a imparcialidade e a independência dos auditores. Os achados de Crabtree, Brandon e Maher (2006), Paulo, 
Cavalcante e Paulo (2013) e Dantas e Medeiros (2015) encontraram evidências de que um longo tempo de auditoria está associado a uma diminuição da qualidade da auditoria.

Nesse ssentido, em razão da perda da indepêndência ao longo dos anos (LYS; WATTS, 1994; DANTAS; MEDEIROS, 2015), do aumento do interesse econômico e da perda da imparcialidade (GAVIOUS, 2007), prevalecem os argumentos a favor de que o menor tempo de auditoria aumentar a qualidade da auditoria e, portanto, espera-se que essa característica seja associada à uma menor assimetria informacional. Diante disso, tem-se a seguinte hipótese:

$H_{1.2}: O$ menor tempo de relacionamento entre auditor e cliente está associado negativamente à assimetria de informações, no período pré e pós-adoção das IFRS.

No que se refere à especialização, trata-se de uma variável intuitiva, uma vez que se relaciona ao conhecimento do auditor sobre um setor específico, indicando que quanto maior for o conhecimento do auditor, maior será a qualidade da auditoria (HU, 2015). Balsam, Krishnan e Yang (2003) encontraram evidências que dão suporte ao fato de que a especialização do auditor melhora a qualidade da auditoria.

Desse modo, é esperado que a especialização da auditoria em um determinado setor seja associada positivamente à qualidade da auditoria (PAULO; CAVALCANTE; PAULO, 2013; DANTAS; MEDEIROS, 2015), e esta por sua vez à redução da assimetria de informação (HEALY; PALEPU, 2001), o que resulta na seguinte hipótese:

$H_{1.3}$ : A especialização da auditoria está associada negativamente à assimetria de informações, no período pré e pós-adoção das IFRS.

Quanto ao atraso na divulgação das informações (Delay), observada a partir da distância entre a data do relatório de auditoria e a data das demonstrações contábeis (CHAMBERS; PENMAN, 1984; NG; TAI, 1994), este traz evidência de possíveis problemas na elaboração das informações contábeis, e isso pode estar associado a uma menor qualidade de informação contábil (PAULO; CAVALCANTE; PAULO, 2013) ou a uma maior probabilidade da emissão de um relatório de auditoria com opinião modificada, conforme evidenciado por Ashton, Willigham e Elliott (1987). Assim, espera-se que quanto maior for o Delay, menor será a qualidade da auditoria e, portanto, maior a assimetria de informações, resultando na seguinte hipótese:

$\mathrm{H}_{1.4}$ : $\mathrm{O}$ menor Delay está associado negativamente à assimetria de informações, no período pré e pós-adoção das IFRS.

Em relação aos honorários de auditoria, a qualidade da auditoria pode estar refletida nos honorários (FRANCIS, 1984). Sob esse argumento, ao analisarem a relação entre tamanho da empresa de auditoria, qualidade e honorários de auditoria, Choi et al. (2010) encontraram evidências de que os honorários estão associados positivamente ao tamanho da empresa e à qualidade da auditoria. Portanto, espera-se que quanto maiores forem os honorários, maior será a qualidade da auditoria e menor a assimetria de informação, o que resulta na hipótese seguinte:

$H_{1.5}$ : Maiores honorários de auditoria estão associados negativamente à assimetria de informações, no período pré e pós-adoção das IFRS.

\section{Procedimentos Metodológicos}

O universo da pesquisa foi inicialmente composto pelas 444 empresas listadas na $B^{3}$. Desse universo foram excluídas: 83 empresas financeiras, em razão de suas peculiaridades operacionais; 124 empresas que não possuíam ações negociadas no período analisado, não sendo possível calcular o bid-ask spread; 80 empresas que somente possuíam informações de negociação em 1 ou 2 anos em um dos períodos pré ou pós-adoção; 6 empresas que passaram por processo de fusão ou cisão, haja vista o potencial de alteração dos valores contábeis, na estrutura organizacional e nos procedimentos operacionais das empresas que participam desse tipo de processo; e, por fim, 1 empresa cujo ciclo operacional encerra-se anualmente em 30/06. Portanto, a amostra final abrangeu 82 empresas.

Considerando os propósitos da pesquisa foi definido para análise o período de 2003 a 2016, isto é, o período de 2003 a 2009 (7 anos) representa a janela de pré-adoção às normas internacionais de contabilidade, enquanto o período de 2010 a 2016 (7 anos) representa o período pós-adoção, uma vez que a partir de 2010 houve a obrigatoriedade de convergência total das demonstrações contábeis consolidadas ao padrão IFRS, conforme determinado pelo Pronunciamento CPC 37 (R1).

\subsection{Modelo e variáveis econométricas}

Segundo achados de Girão e Machado (2013), a proxy mais utilizada nos estudos que mensuram a assimetria de informação é o bid-ask spread, podendo ser representada pela divisão do ponto médio do valor do Bid e do Ask no período da negociação, conforme Amihud e Mendelson (1986):

Onde:

$$
\begin{gathered}
S_{t}=\frac{P_{i t}^{a}-P_{i t}^{b}}{P m_{i t}} \\
P m_{i t}=\frac{P_{i t}^{a}+P_{i t}^{b}}{2}
\end{gathered}
$$

$P_{i t}^{a}=$ oferta de venda (ask) cotado da empresa $i$ no período de tempo $t$; 
$P_{i t}^{b}=$ oferta de compra (bid) cotado da empresa $i$ no período de tempo $t$;

$P m_{i t}=$ ponto médio do preço do Bid e Ask da empresa $i$ no período de tempo $t$;

$S_{i t}=$ bid-ask spread da empresa $i$ no período de tempo $t$.

No presente estudo, o bid-ask spread foi calculado com dados diários, pois segundo Hasbrouck (2007), essa tem sido a metodologia aplicável em base de dados longo prazo. Além disso, o bid-ask spread foi mensurada em dois momentos: antes e após a divulgação contábil, em função do efeito do anúncio dos resultados das empresas. Empresas com gestores oportunistas que atrasam a divulgação de más notícias, na média, provocam uma maior reação do mercado após a divulgação dos resultados (BASU, 1997) e os gestores também têm incentivos de divulgar rapidamente notícias ruins a fim de evitar litígios (SKINNER, 1994), o que provocaria a reação do mercado antes da divulgação dos resultados.

Quanto ao período de abrangência, na literatura é possível identificar a mensuração do bid-ask spread compreendendo diversos períodos, tais como: último dia do ano (AMIHUD; MENDELSON, 1986; WELKER 1995); mensuração diária, com janelas de 2 meses (SILBER, 2005), 2 a 10 dias antes da divulgação contábil e 2 a 30 dias após a divulgação contábil (BHAT; JAYARAMAN, 2010); mensuração diária (FU, KRAFT; ZHANG, 2012; RODRIGUES; GALDI; 2017).

Para a presente pesquisa, adotou-se o período de 30 dias anteriores ao fim do ano fiscal e os primeiros 30 dias posteriores ao primeiro dia de divulgação realizada por uma das empresas da amostra. Desse modo, ao utilizar dois momentos distintos de mensuração do bid-ask spread, é possível capturar o possível efeito do anúncio dos resultados na mensuração da assimetria de informação. Além disso, a escolha do período de 30 dias para mensuração do bid-ask spread tem por fundamento limitar a influência de possíveis efeitos das divulgações trimestrais na assimetria de informação.

Para mensuração da qualidade da auditoria, foram utilizadas as variáveis de Input: tamanho da empresa de auditoria; tempo de auditoria e; especialização da auditoria; de Context: honorários de auditoria, conforme estudos/modelos do FRC (2008), de Francis (2011), Paulo, Cavalcante e Paulo (2013), Knechel et al. (2013), Dantas e Medeiros (2015), IASSB (2014), Hu (2015) e Salehi, Moradi e Paiydarmanesh (2017).

Como proxy para tamanho da empresa de auditoria, adotou que as Big Four do mercado brasileiro, ou seja, para cada ano foram classificadas como "grandes empresas de auditoria" as 4 empresas de auditoria que mais possuem clientes listados na $B^{3}$ (DeANGELO, 1981).

A variável tempo de auditoria foi mensurada conforme os estudos de Dantas e Medeiros (2015) e Paulo, Cavalcante e Paulo (2013), isto é, foi considerado tempo consecutivo em que a auditoria foi realizada pela mesma empresa de auditoria, mensurado em meses. Cumpre mencionar que a base de dados utilizada para coleta do tempo de auditoria (site CVM) não contém as datas de início e término de todos os serviços de auditoria, principalmente no que tange ao período pré-adoção. Quanto ao período pós-adoção, ainda foi possível identificar algumas falhas quanto a essa informação (datas preenchidas de forma padronizada, como por exemplo, data de início 01/01 e a data fim 31/12 de cada período), de modo que tais datas não refletem a exatidão os períodos das auditorias.

Dessa forma, para mitigar os problemas mencionados, para os anos em que a informação de início ou termíno do serviço de auditoria era inexistente, foi considerado como o início em 01/01 e a data final em $31 / 12$ de cada período.

Em relação a mensuração da especialização da auditoria, foi efetuada uma proporção entre a soma da raiz quadrada dos ativos totais dos clientes de um auditor em uma indústria específica e a soma total da raiz quadrada dos ativos totais de todos os clientes do auditor, conforme utilizado por Behn, Choi e Kang (2008) e por Sun e Liu (2011).

De acordo com Ashton, Willigham e Elliott (1987), Ng e Tai (1994), Che-Ahmad e Abidin (2008) e Carslaw e Kaplan (1991), o delay na emissão do relatório de auditoria pode ser estimado pela soma do número de dias entre a data das demonstrações contábeis (31/12) e a data de divulgação do relatório de auditoria, dada pela data da divulgação das demonstrações contábeis.

Vale salientar que a informação sobre as datas de divulgação das demonstrações contábeis foi extraída do site da CVM. Ao pesquisar as referidas datas, observou-se que em diversos casos, principalmente no período pré-adoção, havia somente a data de republicação das demonstrações contábeis, isto é, a data da primeira divulgação não estava disponível. Sendo assim, nesses casos foram considerados como informações não disponíveis ("NA").

Os honorários de auditoria referem-se aos valores totais dos gastos com auditoria independente, conforme utilizado no estudo Salehi, Moradi e Paiydarmanesh (2017). Adicionalmente, o valor dos honorários foi normalizado, dividido pelo valor total dos ativos.

Diante disso, para testar a hipótese do estudo foi especificado um modelo econométrico, estimado na forma de painel, conforme a seguir:

$$
\begin{array}{r}
\text { Spread(Pre1, Pre2, Pos1, Pos2) })_{\text {it }}=\alpha_{1} \text { BIG }_{\text {it }}+\alpha_{2} \text { TA }_{\text {it }}+\alpha_{3} \text { ESP }_{\text {it }}+\alpha_{4} \text { CA }_{\text {it }}+ \\
\alpha_{5} \text { DELAY }_{\text {it }}+\alpha_{6} \text { HON }_{\text {it }}+\alpha_{7} \text { COB }_{\text {it }}+\alpha_{8} \text { TAM }_{\text {it }}+\alpha_{9} \text { INT }_{\text {it }}+\alpha_{10} \text { FLOAT }_{\text {it }}+\alpha_{11} \text { NM }_{\text {it }}+\varepsilon_{\text {it }}
\end{array}
$$


Quadro 1- Resumo das variáveis utilizadas nos modelos de regressão da pesquisa

\begin{tabular}{|c|c|c|}
\hline Código & Descrição da Variável & $\begin{array}{c}\text { Fonte } \\
\text { Relatório }\end{array}$ \\
\hline $\begin{array}{l}\text { Spread } \\
\quad \text { Pre } 1_{\text {it }}\end{array}$ & $\begin{array}{l}\text { Representa a assimetria de informação mensurada pelo bid-ask spread no período } \\
\text { pré-adoção, com base nos últimos } 30 \text { dias do ano fiscal da empresa } i \text { no momento } \\
t \text {. }\end{array}$ & $\begin{array}{l}\text { Thomson } \\
\text { Reuters }\end{array}$ \\
\hline $\begin{array}{l}\text { Spread } \\
\quad \text { Pre2 it }\end{array}$ & $\begin{array}{l}\text { Representa a assimetria de informação mensurada pelo bid-ask spread no período } \\
\text { pré-adoção, com base nos primeiros } 30 \text { dias contar da data em que a primeira } \\
\text { empresa da amostra selecionada divulgou as demonstrações anuais, período que } \\
\text { considera o efeito do anúncio dos resultados na assimetria de informação, da } \\
\text { empresa } i \text { no momento } t \text {. }\end{array}$ & $\begin{array}{l}\text { Thomson } \\
\text { Reuters }\end{array}$ \\
\hline $\begin{array}{l}\text { Spread } \\
\text { Pos1 it }\end{array}$ & $\begin{array}{l}\text { Representa a assimetria de informação mensurada pelo bid-ask spread no período } \\
\text { pós-adoção, com base nos últimos } 30 \text { dias do ano fiscal da empresa } i \text { no momento } \\
t \text {. }\end{array}$ & $\begin{array}{l}\text { Thomson } \\
\text { Reuters }\end{array}$ \\
\hline $\begin{array}{l}\text { Spread } \\
\text { Pos } 2 \text { it }\end{array}$ & $\begin{array}{l}\text { Representa a assimetria de informação mensurada pelo bid-ask spread no período } \\
\text { pós-adoção, com base nos primeiros } 30 \text { dias a contar da data em que a primeira } \\
\text { empresa da amostra selecionada divulgou as demonstrações anuais, período que } \\
\text { considera o efeito do anúncio dos resultados na assimetria de informação, para a } \\
\text { empresa } i \text { no momento } t \text {. }\end{array}$ & $\begin{array}{l}\text { Thomson } \\
\text { Reuters }\end{array}$ \\
\hline$B I G 4_{i t}$ & $\begin{array}{l}\text { Representa o tamanho da empresa de auditoria, mensurada por variável tipo } \\
\text { dummy, onde } 1 \text { se a empresa de auditoria for uma Big Four e, caso contrário, } 0 \text {. }\end{array}$ & $\begin{array}{l}\text { CVM } \\
\text { IAN: } 1.5 \\
\text { FR: } 2\end{array}$ \\
\hline$T A_{i t}$ & $\begin{array}{l}\text { Representa o tempo, em anos consecutivos, de prestação de serviço de auditoria } \\
\text { para a para empresa } i \text { no momento } t \text {. }\end{array}$ & $\begin{array}{l}\text { CVM } \\
\text { IAN: } 1.5 \\
\text { FR:2 }\end{array}$ \\
\hline$E S P_{i t}$ & $\begin{array}{l}\text { Representa a especialização da empresa de auditoria da empresa } i \text { no momento } t \text {, } \\
\text { mensurada pela proporção entre a soma da raiz quadrada dos ativos totais dos } \\
\text { clientes de um auditor em uma indústria específica e a soma total da raiz quadrada } \\
\text { dos ativos totais de todos os clientes do auditor. }\end{array}$ & $\begin{array}{l}\text { Thomson } \\
\text { Reuters }\end{array}$ \\
\hline Delay $_{i t}$ & $\begin{array}{l}\text { Representa o atraso na divulgação do relatório de auditoria da empresa } i \text { no } \\
\text { momento } t \text {, mensurado pela soma do número de dias entre o final do exercício do } \\
\text { ano de referência (31/12) e a data de emissão do relatório de auditoria. }\end{array}$ & $\begin{array}{l}\text { CVM } \\
\text { DFP }\end{array}$ \\
\hline$H O N_{i t}$ & $\begin{array}{l}\text { Honorários de auditoria, mensurado pelo valor total dos gastos com auditoria } \\
\text { independente dividido pelos ativos totais da empresa i no momento } t \text {. }\end{array}$ & $\begin{array}{l}\text { CVM } \\
\text { FR: } 2.1 \text { e } \\
2.2 \\
\end{array}$ \\
\hline$C A_{i t}$ & $\begin{array}{l}\text { Variável tipo dummy para presença do comitê de auditoria, assumindo o valor } 1 \text {, } \\
\text { para empresa } i \text { no momento } t \text {, se a empresa possuir comitê de auditoria e, caso } \\
\text { contrário, } 0 \text { (zero). }\end{array}$ & $\begin{array}{l}\text { CVM } \\
\text { FR: } \\
12.1 \text { e } 12.7 \\
\end{array}$ \\
\hline$C O B_{i t}$ & $\begin{array}{l}\text { Representa a cobertura de analistas da empresa, sendo mensurada pelo logaritmo } \\
\text { natural da quantidade de analistas que emitem recomendações do ativo da } \\
\text { empresa. }\end{array}$ & $\begin{array}{l}\text { Thomson } \\
\text { Reuters }\end{array}$ \\
\hline$T A M_{i t}$ & $\begin{array}{l}\text { Representa o tamanho da empresa, mensurado pelo logaritmo natural do valor total } \\
\text { dos ativos da empresa } i \text { no momento } t \text {. }\end{array}$ & $\begin{array}{l}\text { Thomson } \\
\text { Reuters }\end{array}$ \\
\hline$I N T_{i t}$ & $\begin{array}{l}\text { Representa a internacionalização da empresa i no momento } t \text {, mensurada por meio } \\
\text { de variável tipo dummy, assumindo valor } 1 \text { (um) se a empresa possuir ações } \\
\text { negociadas no mercado norte americano, caso contrário, } 0 \text { (zero). }\end{array}$ & $\begin{array}{l}\text { CVM } \\
\text { FR } 18.7 \\
\quad \text { FC }\end{array}$ \\
\hline$F L O A T_{i t}$ & $\begin{array}{l}\text { Representa o percentual de ações destinadas à livre negociação da empresa } i \text { no } \\
\text { momento } t \text {; }\end{array}$ & $\begin{array}{l}\text { Thomson } \\
\text { Reuters }\end{array}$ \\
\hline$N M_{i t}$ & $\begin{array}{l}\text { Representa o nível de governança diferenciado, mensurado por meio de variável } \\
\text { tipo dummy, assumindo valor } 1 \text { se a empresa pertencer ao Novo Mercado, caso } \\
\text { contrário, } 0 \text { (zero). }\end{array}$ & $\begin{array}{l}\text { CVM } \\
\text { FC }\end{array}$ \\
\hline
\end{tabular}

Nota: Relatório IAN (IAN); Formulário de Referência (FR); Relatório DFP (DFP); Formulário Cadastral (FC).

As variáveis de controle comitê de auditoria (CA), cobertura dos analistas (COB), tamanho da empresa (TAM), internacionalização (INT), free float (FLOAT) e novo mercado (NM) foram inseridas no modelo para dar maior robustez aos resultados encontrados, pois embora não sejam objeto do estudo, a variável dependente pode ser por elas influenciada (RODRIGUES; GALDI, 2017).

Por fim, uma vez que o nível geral de preços tem uma tendência geral de crescer ao longo do tempo, é necessário assegurar que a comparação de preços seja realizada em uma mesma base (BROOKS, 2014). Nesse sentido, para uniformização das informações, todos os dados contábeis foram atualizados para uma mesma data base, por meio do İndice Nacional de Preços ao Consumidor Amplo (IPCA).

\section{Análise dos Resultados}

\subsection{Resultado e análise da estatística descritiva do período pré e pós-adoção}

Como análise inicial, elaborou-se a tabela a seguir com objetivo de descrever e sumarizar o conjunto 
dos dados coletados.

Tabela 1: Estatística descritiva das variáveis no período pré e pós-adoção

\begin{tabular}{|c|c|c|c|c|c|c|c|}
\hline & Variáveis & Média & Mediana & Máximo & Mínimo & Desvio-padrão & Qtde Obs. \\
\hline \multirow{13}{*}{ 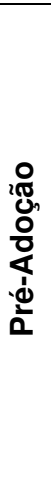 } & Spread Pre.1 & 0,06 & 0,02 & 1,94 & 0,00 & 0,14 & 546 \\
\hline & Spread Pre.2 & 0,07 & 0,02 & 2,00 & 0,00 & 0,17 & 548 \\
\hline & Big4 (Dummy) & 0,72 & 1,00 & 1,00 & 0,00 & 0,45 & 573 \\
\hline & TA & 32,01 & 30,73 & 146,07 & 2,20 & 18,86 & 573 \\
\hline & Esp & 0,52 & 0,42 & 1,00 & 0,03 & 0,33 & 573 \\
\hline & Delay & 79,96 & 79,00 & 317,00 & 27,00 & 32,46 & 423 \\
\hline & Hon & 0,33 & 0,21 & 2,99 & 0,00 & 0,46 & 57 \\
\hline & CA (Dummy) & 0,12 & 0,00 & 1,00 & 0,00 & 0,33 & 573 \\
\hline & Cob & 1,71 & 1,95 & 3,00 & 0,00 & 0,91 & 307 \\
\hline & Tam & 14,96 & 14,88 & 20,11 & 10,21 & 1,88 & 574 \\
\hline & Int (Dummy) & 0,22 & 0,00 & 1,00 & 0,00 & 0,41 & 573 \\
\hline & Float & 72,24 & 94,00 & 100,00 & 0,00 & 34,84 & 546 \\
\hline & NM (Dummy) & 0,13 & 0,00 & 1,00 & 0,00 & 0,34 & 568 \\
\hline \multirow{14}{*}{ 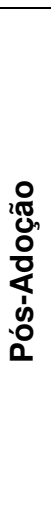 } & Variáveis & Média & Mediana & Máximo & Mínimo & Desvio-padrão & Qtde Obs. \\
\hline & Spread Pos.1 & 0,04 & 0,01 & 1,20 & 0,00 & 0,09 & 561 \\
\hline & Spread Pos.2 & 0,04 & 0,01 & 0,74 & 0,00 & 0,09 & 559 \\
\hline & Big4 (Dummy) & 0,77 & 1,00 & 1,00 & 0,00 & 0,42 & 574 \\
\hline & TA & 34,79 & 32,62 & 170,40 & 0,57 & 23,48 & 574 \\
\hline & Esp & 0,48 & 0,42 & 1,00 & 0,03 & 0,29 & 574 \\
\hline & Delay & 75,74 & 79,00 & 451,00 & 28,00 & 30,90 & 574 \\
\hline & Hon & 0,27 & 0,18 & 2,93 & 0,00 & 0,33 & 525 \\
\hline & CA (Dummy) & 0,30 & 0,00 & 1,00 & 0,00 & 0,46 & 574 \\
\hline & Cob & 2,04 & 2,40 & 3,09 & 0,00 & 0,93 & 312 \\
\hline & Tam & 15,27 & 15,37 & 20,64 & 10,25 & 1,91 & 574 \\
\hline & Int (Dummy) & 0,24 & 0,00 & 1,00 & 0,00 & 0,43 & 574 \\
\hline & Float & 62,81 & 69,00 & 100,00 & 0,00 & 30,01 & 551 \\
\hline & NM (Dummy) & 0,22 & 0,00 & 1,00 & 0,00 & 0,42 & 574 \\
\hline
\end{tabular}

Nota-se que as variáveis que mensuram os Spreads, tanto no modelo pré-adoção quanto do pósadoção, possuem valores similares, o que pode sugerir não haver diferença quando se trata do efeito divulgação das demonstrações contábeis na redução da assimetria de informação, o que poderá ser melhor analisado pelos modelos econométricos.

Em relação as variáveis Big4, CA, Int e NM, nota-se que do período pré para o período pós-adoção houve um aumento nas médias, indicando que as empresas buscaram apresentar medidas de melhorias dado que tais variáveis sinalizam para uma maior qualidade da auditoria (Big 4 e CA) e da governança corporativa (Int e NM).

Para a variável HON, cabe mencionar o baixo número de observações no período pré-adoção, uma vez que as bases de dados utilizadas na pesquisa não possuem informações referentes aos honorários de auditoria.

Quanto às variáveis DELAY e FLOAT, destacam-se os valores de desvio-padrão elevados (32,46 e 34,84 , respectivamente, no período pré-adoção e 30,90 e 30,01, respectivamente, no período pós-adoção), o que demonstra uma certa similaridade e consistência dos dados apurados. Nota-se ainda um maior desviopadrão para o período pré-adoção em relação ao período pós-adoção, o que pode indicar uma melhora na qualidade dos dados.

\subsection{Resultados e análise das estimações com dados em painel}

Para testar a hipótese da pesquisa, foram estimadas quatro regressões com dados em painel, cujos resultados dos testes de robustez são comentados a seguir. Quanto à raiz unitária (testes de Levin, Lin e Chu, Im, Pesaran e Shin, ADF - Fisher e PP - Fisher), não é possível rejeitar a hipótese nula de que a série é não estacionária ( $p$-valores $>0,05$ ) para as variáveis TA e TAM no período pré-adoção, enquanto que para o período pós-adoção não foi possível rejeitar a hipótese nula para as variáveis TA, HON, TAM e FLOAT. Portanto, tais variáveis foram testadas em primeira diferença. Para as demais variáveis, em ambos os períodos, foi possível rejeitar a hipótese nula (p-valores<0,05), portanto, as séries são estacionárias.

No que diz respeito à matriz de correlação, foi identificado que a maior correlação para o período préadoção é de 0,62, entre as variáveis TAM e INT. Para o período pós-adoção, a maior correlação também foi constatada entre as variáveis TAM e INT, cujo valor encontrado foi de 0,68 , indicando uma baixa correlação entre as variáveis para a existência de multicolinearidade. A fim de corroborar com tais resultados foi efetuado o teste Variance Inflation Factor (VIF), tanto para o período pré-adoção quanto para o período pós-adoção, sendo constatado que para cada uma das variáveis não existe valor superior a 5 , indicando que as variáveis 
podem ser testadas em conjunto (WOOLDRIGE, 2012).

A partir do teste Jarque-Bera não foi possível rejeitar a hipótese nula de que os resíduos possuem distribuição normal ( $p$-valores $>0,05$ ). Para investigar a presença de autocorrelação foi realizado o teste $Q$ de Box e Pierce, cujos resultados indicaram p-valores $>0,05$, não sendo possível rejeitar a hipótese nula de que não há autocorrelação.

Por fim, os modelos foram estimados pela matriz de White com efeitos fixos, por duas razões: a) por tratar-se de uma amostra não probabilística, sugere-se a utilização de modelos com efeitos fixos e b) um dos objetivos da pesquisa é comprar os modelos pré e pós-adoção, tornando necessária a utilização dos mesmos modelos econométricos em todas as estimações.

Após a realização dos testes de robustez e definição das especificações que melhor se apliquem aos dados coletados, foram realizadas as estimações dos quatro modelos de regressões propostos, sendo seus resultados resumidos na tabela 2.

Tabela 2: Resultados das estimações no período pré e pós-adoção

\begin{tabular}{|c|c|c|c|c|}
\hline \multirow{2}{*}{ Variáveis } & \multicolumn{4}{|c|}{ Estatística t (prob) } \\
\hline & Modelo 1 & Modelo 2 & Modelo 3 & Modelo 4 \\
\hline $\mathrm{C}$ & $9,52648(0,0000)$ & $10,6037(0,0000)$ & $4,1722(0,0000)$ & $3,4458(0,0007)$ \\
\hline BIG4 & $0,67468(0,5005)$ & $-0,2102(0,8336)$ & $-2,7030(0,0074)^{*}$ & $-2,1773(0,0305)^{\star *}$ \\
\hline TA & $-1,87693(0,0617)^{*}$ & $-4,3719(0,000)^{\star \star \star}$ & $-0,1186(0,9057)$ & $-0,1079(0,9142)$ \\
\hline ESP & $-1,82701(0,0688)^{\star}$ & $-1,8750(0,0619)^{*}$ & $1,5804(0,1154)$ & $1,2355(0,2179)$ \\
\hline DELAY & -- & -- & $1,0114(0,3129)$ & $1,1185(0,2645)$ \\
\hline $\mathrm{HON}$ & -- & -- & $-0,6732(0,5015)$ & $-0,9773(0,3295)$ \\
\hline $\mathrm{CA}$ & $-0,82634(0,4094)$ & $-0,0463(0,9631)$ & $-5,3163(0,0000)^{\star * *}$ & $-2,6180(0,0094)^{\star \star \star}$ \\
\hline $\mathrm{COB}$ & $-3,5045(0,0005)^{\star * *}$ & $-3,1557(0,0018)^{\star \star \star}$ & $-1,8454(0,0663)^{\star}$ & $-2,0326(0,0432)^{\star *}$ \\
\hline TAM & $0,55416(0,5800)$ & $0,2613(0,7940)$ & $-0,5553(0,5792)$ & $-0,9376(0,3494)$ \\
\hline INT & $-0,68244(0,4956)$ & $-0,5496(0,5830)$ & $-3,0294(0,0027)^{\star \star \star}$ & $-2,8404(0,0049)^{\star \star \star *}$ \\
\hline FLOAT & $-6,05809(0,0000)^{\star * \star}$ & $-2,1229(0,0347)^{\star \star}$ & $-2,9145(0,0039)^{\star * *}$ & $-1,9987(0,0468)^{\star \star}$ \\
\hline NM & $-4,03397(0,0001)^{\star * *}$ & $-4,0658(0,0001)^{\star * *}$ & $0,9297(0,3535)$ & $-0,7421(0,4588)$ \\
\hline Efeitos & Fixos & Fixos & Fixos & Fixos \\
\hline №. de Obs. & 274 & 274 & 246 & 246 \\
\hline $\mathrm{R}^{2}$ & 0,2490 & 0,1832 & 0,2728 & 0,2775 \\
\hline $\mathrm{R}^{2}$ Ajustado & 0,2084 & 0,1390 & 0,2220 & 0,2270 \\
\hline Estatística F & 6,1344 & 4,1481 & 5,3701 & 5,4966 \\
\hline Prob. F & 0,0000 & 0,0000 & 0,0000 & 0,0000 \\
\hline
\end{tabular}

Nota: Os Modelos 1, 2, 3 e 4 referem-se às estimações dos modelos Pre1, Pre2, Pos1 e Pos2, respectivamente. ${ }^{* * *},{ }^{* *} e^{*}$ denotam a significância estatística nos níveis de $1 \%, 5 \%$ e $10 \%$, respectivamente. Os modelos préadoção foram estimados sem as variáveis DELAY e HON, haja vista que não existem informações sobre valores de honorários de auditoria nas bases de dados pesquisadas, assim como existem diversas lacunas de informações quando à data de publicação das demonstrações contábeis, o que resultaria na redução de cerca de $30 \%$ no número de observações (de 274 para 190 ).

Inicialmente, nota-se que os p-valores das estatísticas $F$ são menores do que 0,05 , o que indica que as variáveis em conjunto são significantes para explicar à variável dependente. Além disso, os resultados demonstram que as variáveis explicam aproximadamente entre $25 \%$ e $18 \%$ das variações ocorridas na variável SPREAD nos modelos pré-adoção $\left(R^{2}\right)$ e aproximadamente $28 \%$ nos modelos pós-adoção, indicando que os elementos da qualidade da auditoria têm maior poder explicativo no período pós-adoção em relação ao período pré-adoção.

Aparentemente, o fator - emissão do relatório de auditoria - não causou diferenças relevantes nos resultados, uma vez que os resultados dos modelos pré e pós-divulgação, tanto nos modelos pré-adoção como nos modelos pós-adoção, apresentam consistência nos resultados, isto é, as variáveis com significância estatística no modelo pré-divulgação também apresentaram significância estatística nos modelos pósdivulgação, todos com sinais no mesmo sentido.

Quanto à variável BIG4, nota-se que os coeficientes possuem significância somente no período pósadoção, os quais apresentam relação negativa em relação ao Spread. Desse modo, esses resultados sugerem que, no período pós-adoção, quanto maior a empresa de auditoria, maior será a qualidade da auditoria e, consequentemente, menor será a assimetria de informação.

Os resultados em análise corroboram os resultados anteriores entre qualidade da auditoria e as Big Four identificados por DeAngelo (1981), Becker et al. (1998), Healy e Palepu (2001), Francis (2004), Fafatas (2010), Paulo, Cavalcante e Paulo (2013) e Hu (2015), assim como com os achados de Francis, Maydew e Sparks (1999), Francis (2004) e Francis e Yu (2009), os quais encontraram evidências de que o tamanho da empresa de auditoria está associado positivamente à qualidade da auditoria. Assim, a assocação positiva entre qualidade da auditoria e as Big Four evidenciada reforçam os argumentos de que grandes empresas de auditoria podem propiciar um ambiente de maior qualidade da informação contábil (FRANCIS, 2004; ALMEIDA; ALMEIDA, 2009) atuando como agentes para realização de uma melhor prática contábil nesse período, e portanto, uma maior fidedignidade das demonstrações contábeis (FRANCIS; MAYDEW; SPARKS, 
1999) no período pós-adoção.

Em relação à variável TA, esperava-se que o menor tempo de auditoria estivesse associado à maior qualidade da informação contábil, conforme evidências de Lys e Watts (1994), Crabtree, Brandon e Maher (2006), Gavious (2007), Paulo, Cavalcante e Paulo (2013) e Dantas e Medeiros (2015). No entanto, tal hipótese não foi corroborada.

O que se verificou é que o maior tempo de auditoria, no período pré-adoção, está associado à uma menor assimetria informacional, indicando que um maior conhecimento do auditor sobre as empresas aumenta a probabilidade de detecções de distorções relevantes nas demonstrações contábeis $(\mathrm{GAO}, 2003)$ e melhora as condições de avaliarem as decisões gerenciais que podem influenciar as demonstrações contábeis (MYERS; MYERS; OMER, 2003), gerando assim a divulgação de informações contábeis com maior qualidade, proporcionando um ambiente de menor assimetria de informações. Tal achado vai de encontro aos resultados de estudos anteriores de Lys e Watts (1994), Dantas e Medeiros (2015), Gavious (2007) e Siregar et al. (2012).

Chama atenção também o fato de que o tempo de auditoria, significante no período pré-convergência, deixa ser no período pós-convergência (apesar de manter o sentido). Esse resultado pode derivar do conjunto de normas mais subjetivas e de variáveis mais objetivas que expliquem a melhor atuação da auditoria independente quanto à qualidade da informação contábil, independentemente do tempo que a mesma esteja atuando.

Adicionalmente, constata-se também que no período pré-adoção, quando a variável maior tempo de auditoria é significativa e negativa, a variável - comitê de auditoria - não é significativa; enquanto que essa relação se inverte no período pós-adoção, passando esta variável (CA) ser significativa enquanto maior TA deixa de ser. Esse resultado evidencia que no período pós-convergência a atuação do CA assegura melhorias na redução da assimetria mesmo quando há um maior tempo de permanência da empresa de auditoria, o que em certa medida corrobora o que preconiza a ICVM 308/1999, art. 31-A com redação dada pela ICVM 611/2019, para o período pós-adoção.

Para variável ESP, verifica-se que as relações esperadas foram identificadas tão somente nos modelos pré-adoção, os quais apresentaram significância estatística. Esses resultados corroboram com as expectativas quanto à especialização da auditoria em aumentar a sua qualidade e reduzir a assimetria de informação. Portanto, os resultados evidenciados nos modelos pré-adoção se alinham aos argumentos de Balsam, Krishnan e Yang (2003), Solomon, Shields e Whittington (2009), Paulo, Cavalcante e Paulo (2013), Dantas e Medeiros (2015) e Hu (2015), no sentido de que uma maior especialização pode aumentar o conhecimento do auditor (HU, 2015), possibilitando uma melhor análise das demonstrações contábeis e favorecendo a detecção de erros (SOLOMON; SHIELDS; WHITTINGTON, 2009), o que favorece a qualidade da auditoria.

Para as variáveis DELAY e HON, as estimações foram realizadas somente para o período pósadoção, uma vez que em decorrência indisponibilidade de informações para essas variáveis, para algumas empresas e em alguns anos, gerava a diminuição da quantidade total de observações utilizadas nas regressões.

Para o período pós-adoção, as relações encontradas estão de acordo com aquelas esperadas nos dois modelos, isto é, foi evidenciada uma relação positiva entre o DELAY e a SPREAD e uma relação negativa entre as variáveis HON e SPREAD. Porém, tais resultados não apresentaram coeficientes com significância estatística. Portanto, a indicação é de que o atraso na divulgação das demonstrações contábeis e os o valor dos honorários de auditoria não impactam de forma relevante a qualidade da auditoria e a assimetria de informação.

Com relação à variável $\mathrm{CA}$, os resultados apurados possuem sinais negativos em todos os modelos, conforme esperado. Além disso, nos dois modelos pós-adoção, os coeficientes foram significativos, sugerindo menor assimetria de informação quando há comitê de auditoria.

O resultado em análise pode indicar que, no período pós-adoção, o comitê de auditoria pode propiciar um ambiente de maior independência para na auditoria (PAULO, CAVALCANTE; PAULO, 2013; DANTAS; MEDEIROS, 2015), com menor interferência da administração (KOCH; WEBER; WÜSTEMANN, 2012), de forma a melhorar a qualidade do trabalho realizado (PAULO; CAVALCANTE; PAULO, 2013) e, por conseguinte, melhorar a informação divulgada e reduzir a assimetria de informação.

No que se refere à variável $C O B$, é possível observar um comportamento consistente em todos os modelos, apresentando $p$-valores significativos e associação negativa em relação ao SPREAD. Assim, os resultados sugerem que a maior cobertura de analistas reduz a assimetria de informação. Esse resultado reforça os argumentos de Healy e Palepu (2001), no sentido de que os analistas revelam informações que reduzem a assimetria de informação, assim como corrobora com os achados de Chang et al. (2008), Aslan, et al. (2011) e Rodrigues e Galdi (2017).

Em relação à variável TAM, os sinais dos coeficientes apurados no período pré-adoção foram contrários aos esperados, isto é, esperava-se uma relação negativa entre o tamanho da empresa e a assimetria de informação, porém os sinais apresentados foram positivos, enquanto no período pós-adoção a relação observada foi negativa, conforme esperado. Vale frisar que ambos os resultados apresentaram coeficientes sem significância estatística. 
No que diz respeito à variável INT, os resultados também demonstram coerência em razão das relações negativas identificadas em todos os modelos. Vale destacar, entretanto, que a significância estatística somente foi observada nos modelos pós-adoção, o que possibilita argumentar que nesse período a internacionalização da empresa é um fator que contribuiu para a redução da assimetria de informação, isto é, entende-se que a participação no mercado internacional, por exigir uma maior divulgação de informações em decorrência das exigências dos órgãos reguladores internacionais, pode criar um cenário com menor assimetria de informação.

Quanto a variável FLOAT, todos os sinais apresentaram relação negativa com a assimetria de informação e coeficientes com significância estatística. Esses resultados permitem corroborar com os resultados encontrados por Chang et al. (2008), os quais evidenciaram que um maior percentual de disponibilidade de ações destinadas à livre negociação gera uma menor assimetria de informação.

Com relação à variável NM, esperava-se uma associação negativa com a assimetria de informação, a qual foi corroborada nos resultados apresentados no período pré-adoção. Já para o período pós-adoção apurou-se um modelo com associação positiva e outro com associação negativa, ambos sem significância estatística.

Os resultados em análise permitem defender alegações no sentido de que o fato de empresas estarem listadas no Novo Mercado da BOVESPA, em que é exigido um maior nível de governança corporativa, transparência e disponibilidade das informações contábeis, indicam uma melhor qualidade das informações contábeis divulgadas, o que pode reduzir a assimetria de informação. Contudo, tal constatação restringe-se ao período pré-adoção. Cumpre destacar os resultados para listagem no Novo Mercado da Bovespa no período pós-adoção, não corrobora com os resultados apurados no estudo de Rodrigues e Galdi (2017).

Sob o ponto de vista comparativo entre os períodos, esperava-se encontrar evidências que corroborassem o entendimento de que a adoção das IFRS indicaria maior qualidade da informação contábil, da auditoria e menor assimetria de informação. Portanto, a hipótese construída foi fundamentada no fato de que o período pós-adoção evidenciaria uma maior qualidade da auditoria, representada por um maior poder explicativo nos modelos estimados no período pós-adoção em relação ao período pré-adoção.

Nesse sentido, considerando as estimações na forma contemporânea (modelos Pre1 e Pos1), os resultados apurados demonstram uma diferença no poder explicativo dos modelos. O modelo Pre1 apresentou um $\mathrm{R}^{2}$ de $24,90 \%$, enquanto no modelo Pos1 foi apurado o percentual de 27,28\%. Esse resultado sugere que há uma percepção de maior relevância da qualidade da auditoria na redução da assimetria de informação no período pós-adoção do que o período pré-adoção.

Nota-se também que as variáveis BIG4 e CA foram significantes no período pós-adoção, enquanto as variáveis TA e ESP foram significantes no período pré-adoção. Esse resultado sugere que ser uma BIG4 e/ou possuir comitê de auditoria são elementos associados à redução da assimetria de informação no período pós-adoção, sendo um possível reflexo do volume de conhecimento e dos aspectos técnicos das competências do auditor obtidos na aplicação das IFRS, assim como a contribuição do comitê de auditoria para independência da auditoria.

É possível argumentar também que a perda da relevância das variáveis TA e ESP entre os períodos pré e pós-adoção pode ter sido em razão da obrigatoriedade do cumprimento das IFRS, isto é, ao aplicar o padrão contábil internacional, uma norma que pode melhorar a qualidade da divulgação contábil (BARTH; LANDSMAN; LANG, 2008), fatores mais específicos relacionados às características da auditoria, como o TA e ESP, passaram a ser supridos pela IFRS.

Outra questão que pode explicar a relevância do atributo de qualidade da auditoria BIG4 e CA (variável de controle) é o fato de que as IFRS possibilitam um cenário em que haja maior qualidade da informação contábil (BARTOV; GOLDBEG, KIM, 2005; BARTH; LANDSMAN; LANG, 2008), permitindo uma maior discricionariedade dos gestores (BAPTISTA, 2009), sendo que maiores empresas de auditoria (BIG4) e o CA sinalizam de forma mais objetiva para o mercado financeiro uma melhor atuação na asseguração da informação divulgada e sua qualidade.

No que se refere à comparação entre a qualidade da auditoria nos períodos pré e pós-adoção com lag (modelos Pre2 e Pos2), percebe-se resultados semelhantes aos modelos contemporâneos, com resultados apurados demonstrando uma diferença mais relevante no poder explicativo entre os modelos. $O$ modelo Pre2 apresentou um $\mathrm{R}^{2} 18 \%$, enquanto no modelo Pos2 foi apurado um $\mathrm{R}^{2}$ de $28 \%$, corroborando uma maior relevância no papel da auditoria independente na redução da assimetria informacional em um ambiente cuja informação é elaborada com maior discricionariedade.

\subsection{Teste de sensibilidade do bid-ask spread}

Considerando que a mensuração da variável bid-ask spread (assimetria) é realizada por diferentes formas, conforme estudos anteriores (AMIHUD; MENDELSON, 1986; WELKER 1995; SILBER, 2005; BHAT; JAYARAMAN, 2010; FU, KRAFT; ZHANG, 2012; RODRIGUES; GALDI; 2017), esta seção buscou testar se os resultados do estudo apresentam-se consistentes a partir da adoção da mensuração da assimetria com base em outros períodos. 
Sendo assim, em adição às estimações da seção anterior, a qual valeu-se do período de 30 dias para mensurar a assimetria, foram efetuadas mensurações do bid-ask spread considerando os períodos de 7, 15 e 90 dias, a fim de identificar se o período adotado influenciaria os resultados apurados.

Foram adotados os mesmos procedimentos para aferir a robustez das equações, cujos resultados são apresentados nos quadros 2 e 3.

Quadro 2: Resultado do teste de sensibilidade no período pré-adoção

\begin{tabular}{|c|c|c|c|c|c|c|c|c|c|}
\hline \multirow{2}{*}{$\begin{array}{c}\text { Variáveis } \\
\text { independente } \\
\mathrm{s}\end{array}$} & \multirow{2}{*}{$\begin{array}{c}\text { Sinal } \\
\text { esperado }\end{array}$} & \multicolumn{8}{|c|}{ Sinal observado } \\
\hline & & SPRE7 & SPOS7 & SPRE15 & SPOS15 & SPRE30 & $\begin{array}{c}\text { SPOS3 } \\
0\end{array}$ & SPRE90 & SPOS90 \\
\hline BIG4 & $(-)$ & $(+)$ & $(-)$ & $(+)$ & $(+)$ & $(+)$ & $(-)$ & $(+)$ & $(-)$ \\
\hline $\mathrm{D}(\mathrm{TA})$ & $(+)$ & $(+)$ & $(-)$ & $(-)$ & $(-)^{\star \star \star}$ & $(-)^{\star}$ & $(-)^{* * \star}$ & $(-)^{\star \star}$ & $(-)^{\star \star \star}$ \\
\hline ESP & $(-)$ & $(-)^{*}$ & $(-)^{\star \star}$ & $(-)^{*}$ & $(-)^{\star \star}$ & $(-)^{*}$ & $(-)^{*}$ & $(-)$ & $(-)^{*}$ \\
\hline CA & $(-)$ & $(-)$ & $(-)$ & $(-)$ & $(-)$ & $(-)$ & $(-)$ & $(-)$ & $(+)$ \\
\hline COB & $(-)$ & $(-)^{\star \star \star}$ & $(-)^{\star \star \star *}$ & $(-)^{* * \star}$ & $(-)^{\star \star \star}$ & $(-)^{* * *}$ & $(-)^{* * \star}$ & $(-)^{\star \star \star}$ & $(-)^{\star \star \star}$ \\
\hline D(TAM) & $(-)$ & $(-)$ & $(-)$ & $(+)$ & $(+)$ & $(+)$ & $(+)$ & $(+)$ & $(-)$ \\
\hline INT & $(-)$ & $(-)$ & $(-)$ & $(-)$ & $(-)$ & $(-)$ & $(-)$ & $(-)$ & $(-)$ \\
\hline FLOAT & $(-)$ & $(-)^{\star \star \star}$ & $(-)^{\star \star \star}$ & $(-)^{* * \star}$ & $(-)^{* \star \star}$ & $(-)^{* \star \star}$ & $(-)^{* *}$ & $(-)^{\star \star \star \star}$ & $(-)^{* *}$ \\
\hline NM & $(-)$ & $(-)^{\star \star \star}$ & $(-)^{* *}$ & $(-)^{\star \star \star}$ & $(-)^{\star \star \star}$ & $(-)^{\star * \star}$ & $(-)^{* \star \star}$ & $(-)^{* \star *}$ & $(-)^{\star * \star}$ \\
\hline
\end{tabular}

Nota: ${ }^{* *},{ }^{* *} \mathrm{e}^{*}$ denotam a significância estatística nos níveis de $1 \%, 5 \%$ e $10 \%$, respectivamente.

Os resultados apurados demonstram consistência com as estimações do bid-ask spread de 30 dias, sugerindo que o período selecionado para composição da variável bid-ask spread não afeta significativamente os resultados.

No período pré-adoção, quase todos os testes das variáveis de qualidade de auditoria TA e ESP possuem com significância estatística, sendo todos eles com coeficientes negativos. Além disso, em todos os testes, as variáveis de controle COB, FLOAT e NM demonstraram significância estatística e também com sinais no mesmo sentido. Já as demais variáveis, BIG4, CA, TAM e INT, não apresentaram significância estatística em nenhum dos testes. A seguir apresenta-se os resultados para o período pós-convergência.

\begin{tabular}{|c|c|c|c|c|c|c|c|c|c|}
\hline \multirow{3}{*}{$\begin{array}{c}\text { Variáveis } \\
\text { Independentes }\end{array}$} & \multirow{3}{*}{$\begin{array}{c}\text { Sinal } \\
\text { esperad } \\
0\end{array}$} & \multirow{2}{*}{\multicolumn{8}{|c|}{ Sinal observado }} \\
\hline & & & & & & & & & \\
\hline & & SPRE7 & SPOS7 & SPRE15 & SPOS15 & SPRE30 & SPOS30 & SPRE90 & SPOS90 \\
\hline BIG4 & $(-)$ & $(-)^{* \star \star}$ & $(-)^{\star \star}$ & $(-)^{\star \star \star}$ & $(-)^{\star \star}$ & $(-)^{\star \star \star}$ & $(-)^{\star \star}$ & $(-)^{\star \star \star}$ & $(-)^{\star *}$ \\
\hline $\mathrm{D}(\mathrm{TA})$ & $(+)$ & $(+)$ & $(-)$ & $(+)^{* *}$ & $(-)$ & $(-)$ & $(-)$ & $(+)$ & $(-)$ \\
\hline ESP & $(-)$ & $(+)$ & $(+)$ & $(+)$ & $(+)^{*}$ & $(+)$ & $(+)$ & $(+)$ & $(+)$ \\
\hline DELAY & $(+)$ & $(+)$ & $(+)$ & $(+)$ & $(+)$ & $(+)$ & $(+)$ & $(+)$ & $(+)$ \\
\hline $\mathrm{D}(\mathrm{HON})$ & $(-)$ & $(-)$ & $(-)$ & $(-)$ & $(-)$ & $(-)$ & $(-)$ & $(-)$ & $(-)$ \\
\hline CA & $(-)$ & $(-)^{\star \star \star *}$ & $(-)^{\star \star *}$ & $(-)^{\star \star \star}$ & $(-)^{\star \star \star}$ & $(-)^{\star \star \star}$ & $(-)^{* * \star}$ & $(-)^{\star \star \star}$ & $(-)^{\star \star \star *}$ \\
\hline COB & $(-)$ & $(-)^{\star *}$ & $(-)^{*}$ & $(-)^{\star \star \star}$ & $(-)$ & $(-)^{*}$ & $(-)^{* *}$ & $(-)^{* *}$ & $(-)^{*}$ \\
\hline D(TAM) & $(-)$ & $(-)$ & $(-)$ & $(-)$ & $(-)$ & $(-)$ & $(-)$ & $(-)$ & $(-)$ \\
\hline INT & $(-)$ & $\frac{1}{(-)^{\star \star \star}}$ & $(-)^{* *}$ & $(-)^{* * *}$ & $(-)^{\star * *}$ & $(-)^{* * *}$ & $(-)^{* * *}$ & $(-)^{\star * \star}$ & $\frac{1}{(-)^{* * *}}$ \\
\hline D(FLOAT) & $(-)$ & $(-)^{*}$ & $(-)^{*}$ & $(-)$ & $(-)^{*}$ & $(-)^{\star \star \star}$ & $(-)^{* *}$ & $(-)^{\star * *}$ & $(-)^{* *}$ \\
\hline NM & $(-)$ & $(+)$ & $(-)$ & $(-)$ & $(+)$ & $(+)$ & $(-)$ & $(+)$ & $(-)$ \\
\hline
\end{tabular}

Em relação ao período pós-adoção, similarmente às apurações dos testes no período pré-adoção, os resultados apresentam consistência. A variável BIG4 demonstra significância e coeficientes negativos em todos os testes. Já para as variáveis de controle $\mathrm{CA}$ e $\mathrm{COB}$, os resultados demonstram significância e sinais negativos em todos os testes, enquanto para as variáveis INT e FLOAT, os coeficientes também foram negativos em todos os testes e com significâncias em 7 dos 8 testes realizados.

Por fim, as variáveis TA e ESP somente apresentaram significância em 1 dos 8 testes realizados. As variáveis DELAY, HON e TAM apresentaram coeficientes na mesma direção em todos os testes, porém nenhum com significância estatística e a variável NM não apresentou um padrão nos sinais e nem significância nos resultados.

Desse modo, os testes de sensibilidade de 7, 15 e 90 dias demonstram consistência com as estimações realizadas considerando o período de abrangência do bid-ask spread de 30 dias. Além disso, os resultados pré e pós-divulgação não impactam de forma diferente a assimetria de informação, reforçando a ideia da Hipótese de Mercado Eficiente semiforte proposta por Fama (1970), isto é, o preço dos ativos incorporam as informações públicas disponíveis antes da divulgação contábil.

\section{Considerações Finais}

Com o objetivo de avaliar a influência da qualidade da auditoria na assimetria de informação nas empresas abertas listadas na $B^{3}$, nos períodos pré e pós-adoção das IFRS, este estudo apresenta evidências 
da importância da qualidade da auditoria na redução da assimetria informacional, especialmente no período pós-convergência.

De modo geral, todos os resultados com significância estatística apurados (BIG4, TA, ESP, CA, COB, INT, FLOAT e NM) foram consistentes como os resultados esperados, exceto a variável TA, sugerindo que os elementos de qualidade da auditoria BIG4, TA e ESP melhoram a qualidade da informação contábil e reduzem a assimetria de informação. Vale destacar que houve significância estatística das variáveis de qualidade da auditoria TA e ESP no período pré-adoção e das variáveis BIG4 e CA no período pós-adoção. Essa mudança de variáveis pode estar relacionada à maior ênfase dada aos aspectos relacionados à relevância e à experiência da auditoria para lidar a adoção da IFRS e mitigar riscos de novos casos de fraudes contábeis, assim como à função do comitê da auditoria em contribuir para a independência da auditoria independente.

Quanto a listagem no novo mercado constata-se como elemento que reduz a assimetria de informação no período pré-adoção, enquanto a maior cobertura de analistas está associada à redução da assimetria de informação em ambos os períodos e a internacionalização da empresa está relacionada à redução da assimetria de informação somente no período pós-adoção.

Ao analisar os resultados com enfoque comparativo entre o período pré e pós-adoção, notou-se consistência nos resultados, uma vez que não existem coeficientes significativos com sinais divergentes para uma mesma variável.

As variáveis $\mathrm{COB}$ e FLOAT foram as únicas que apresentaram coeficientes com significância em todos os modelos e apontando para uma mesma direção, sugerindo que quanto maior a quantidade de analistas que recomendam a empresa e quanto maior a disponibilidade de ações disponíveis para negociação, menor é a assimetria de informação.

No que concerne à comparação da qualidade da auditoria entre os períodos pré e pós-adoção das IFRS, apurou-se um maior poder explicativo dos modelos que estimam o período pós-adoção em relação ao período pré-adoção ( $R^{2}$ Ajustado), sugerindo que os elementos de mensuração da qualidade da auditoria são mais relevantes para a redução da assimetria de informação no período pós-adoção do que no período préadoção.

Com isso, o estudo, ao mostrar quais elementos podem sugerir uma melhorar da qualidade da auditoria, pode contribuir com a literatura no papel de consolidar atributos relacionados à qualidade da auditoria que possibilitam um ganho quanto à qualidade informacional, e, portanto, que podem mitigar a assimetria informacional. Vale destacar que os resultados analisados também podem contribuir para que os reguladores avaliem, sejam os que atuam sobre o mercado de capitais, quer sejam nos órgãos normatizadores de práticas contábeis, os impactos da adoção das IFRS em relação à qualidade da informação contábil, em especial pelo fato de no período pós-adoção constatar-se que maior tempo de auditoria está associada a existência de comitê de auditoria, conforme preconiza a ICVM 308/1999, art. 31-A com redação dada pela ICVM 611/2019. Além disso, os investidores podem, ao avaliar as características relacionadas à qualidade da auditoria, identificar quais empresas são mais propensas a possuir uma maior qualidade informacional, de modo a avaliarem ou reavaliarem seus possíveis métodos de alocação de investimentos.

Como limitações do estudo, pode-se elencar: a ausência de informações quanto aos honorários de auditoria no período pré-adoção; a falta de informações sobre a data de divulgação das demonstrações contábeis, para algumas empresas e em alguns anos e, por fim, as escolhas dos modelos de mensuração do bid-ask spread e das variáveis de controle, que dependem da escolha do pesquisador, a exemplo da variável de governança corporativa.

Com relação às sugestões para trabalhos futuros, tem-se: a) investigar a relação entre a qualidade da auditoria e o gerenciamento de resultados nos período pré e pós-adoção das IFRS; b) ampliar os testes estatísticos quanto ao período de abrangência do bid-ask spread, de forma a contemplar os outros trimestres e; c) utilizar outros modelos de mensuração de assimetria de informação e da qualidade da auditoria.

\section{Referências}

ALMEIDA, J. E. F. de; ALMEIDA, J. C. G. de. Auditoria e earnings management: estudo empírico nas empresas abertas auditadas pelas big four e demais firmas de auditoria. Revista Contabilidade \& Finanças, USP, São Paulo, v. 20, n. 50, p. 62-74. 2009. https://doi.org/10.1590/S151970772009000200005.

AMIHUD, Y.; MENDELSON, H. Asset pricing and the bid-ask spread. Journal of Financial Economics, v. 17, p. 223-249. 1986. https://doi.org/10.1016/0304-405X(86)90065-6.

ASHBAUGH, H. Non-US Firms' Accounting Standard Choices. Journal of Accounting and Public Policy, v. 20, p. 129-153, 2001. https://doi.org/10.1016/S0278-4254(01)00025-4.

ASHTON, R. H.; WILLINGHAM, J. J.; ELLIOTT, R. K.An Empirical Analysis of Audit Delay. Journal of Accounting Research, v. 25, n. 2, pp. 275-292, 1987. https://www.jstor.org/stable/2491018.

ASLAN, H. et al. The characteristics of informed trading: implications for asset pricing. Journal of Empirical 
Finance, n. 18, p. 782-801, 2011. https://doi.org/10.1016/j.jempfin.2011.08.001.

ATTIG, N. et al. Effects of large shareholding on information asymmetry and stock liquidity. Journal of Banking \& Finance, v. 30. p. 2875-2892, 2006. https://doi.org/10.1016/j.jbankfin.2005.12.002.

BALL, R.; SHIVAKUMAR, L. Earnings quality in UK private firms: comparative loss recognition timeliness. Journal of Accounting and Economics, n. 39, p. 83-128, 2005.

https://doi.org/10.1016/j.jacceco.2004.04.001.

BALSAM, S.; KRISHNAN, J.; YANG, J. S. Auditor Industry Specialization and Earnings Quality. A Journal of Practice \& Theory. v. 22, n. 2, p. 71-97, 2003. https://doi.org/10.2308/aud.2003.22.2.71.

BAPTISTA, E. M. B. Ganhos em transparência versus novos instrumentos de manipulação: o paradoxo das modificações trazidas pela lei no 11.638. Revista de Administração de Empresas, v. 49, n. 2, p. 234-239, 2009. https://doi.org/10.1590/S0034-75902009000200009.

BARTH, M. E.; LANDSMAN, W. R.; LANG, M. H. International Accounting Standards and Accounting Quality. Journal of Accounting Research, v. 46, n. 3, 2008. https://doi.org/10.1111/j.1475679X.2008.00287.X.

BARTOV, E.; GOLDBERG, S. R.; KIM, M. Comparative Value Relevance Among German, U.S., and International Accounting Standards: A German Stock Market Perspective. Journal of Accounting and Economics, v. 20, n. 2, p. 95-119, 2005. https://doi.org/10.1177/0148558X0502000201.

BASU, S. The conservatism principle and the asymmetric timeliness of earnings. Journal of Accounting and Economics, n. 24, p. 3-37, 1997. https://doi.org/10.1016/S0165-4101(97)00014-1.

BEATTY, A.; HARRIS, D. G. The Effects of Taxes, Agency Costs and Information Asymmetry on Earnings Management: A Comparison of Public and Private Firms. Review of Accounting Studies, v. 3, p. 299-326, 1998.

BEAVER, W. H. The information content of annual earnings announcements. Journal of Accounting Research. v. 6, p. 67-92, 1968. https://www.jstor.org/stable/2490070.

BEHN, B. K.; CHOI, J.; KANG, T. Audit Quality and Properties of Analyst Earnings Forecasts. The Accounting Review, v. 83, n. 2, p. 327-349, 2008. https://www.jstor.org/stable/30245360.

BECKER, C. L. et al. The Effect of Audit Quality on Earnings Management. Contemporary Accounting Research. v. 15, n. 1, p. 1-24, 1998. https://doi.org/10.1111/j.1911-3846.1998.tb00547.x.

BIDDLE, G. C.; HILARY, G. Accounting Quality and Firm-Level Capital Investment. The Accounting Review, v. 81, n. 5, p. 963-982, p. 189-204, 2006. https://www.jstor.org/stable/4093094.

BHAT, G.; JAYARAMAN, S. Information Asymmetry around Bank Earnings Announcements during the Financial Crisis. Financial Accounting and Reporting Section. 2010. http://dx.doi.org/10.2139/ssrn.1465193.

BHATTACHARYA, U.; SPIEGEL, M. Insiders, outsiders, and market breakdowns. The Review of Financial Studies, v. 4, n. 2, p. 255-282, 1991. https://doi.org/10.1093/rfs/4.2.255.

BOMFIM, M. P. et al. Adoção ao padrão IFRS e suavização dos resultados nas seguradoras brasileiras. Revista Universo Contábil, v.12, n. 4. p. 152-171, 2016. DOI: https://doi.org/10.4270/RUC.2016432.

BRASIL. CPC 37 (R1) - Adoção Inicial das Normas Internacionais de Contabilidade. Disponível em: <http://www.cpc.org.br/CPC/Documentos-Emitidos/Pronunciamentos>. Acesso em: 10.07.2017.

BRASIL. NBC TA 200 - Objetivos Gerais do Auditor Independente e a Condução da Auditoria em Conformidade com Normas de Auditoria. Disponível em:

<http://www2.cfc.org.br/sisweb/sre/detalhes_sre.aspx?Codigo=2016/NBCTA200(R1)>. Acesso em: 10.07.2017.

BROOKS, C. Introductory econometrics for finance. $3^{\text {rd }}$ Edition. Cambridge University Press. New York, 2014.

CARSLAW, C. A. P. N.; KAPLAN, S. E. An Examination Further Evidence of Audit Delay: from New Zealand. Accounting and Business Research, v. 22, n. 85, p. 21-32, 1991. https://doi.org/10.1080/00014788.1991.9729414.

CHADEGANI, A. A. Review of studies on audit quality. International Conference on Humanities, Society and Culture, IACSIT Press, Singapura, v. 20, 2011. SSRN. Recuperado em 17 de jun de 2017. http://dx.doi.org/10.2139/ssrn.2227359.

CHAMBERS, A. E.; PENMAN, S. H. Timeliness of Reporting and the Stock Price Reaction to Earnings 
Announcements. Journal of Accounting Research, v. 22, n. 1, 1984. https://www.jstor.org/stable/2490700.

CHANG, M. et al. Does disclosure quality via investor relations affect information asymmetry? Australian Journal of Management, n. 33, v. 2, pp. 375-390, 2008. https://doi.org/10.1177/031289620803300208.

CHE-AHMAD, A.; ABIDIN, S. Audit Delay of Listed Companies: A Case of Malaysia. International Business Research, v. 1, n. 4, 2008. https://doi.org/10.5539/ibr.v1n4p32.

CHEN, H.; TANG, Q.; JIANG, Y.; LIN, Z. The role of international financial reporting standards in accounting quality: Evidence from the European Union. Journal of International Financial Management \& Accounting, v. 21, n. 3, p. 220-278, 2010. https://doi.org/10.1111/j.1467-646X.2010.01041.x.

$\mathrm{CHOI}$, J. et al. Audit Office Size, Audit Quality and Audit Pricing. Auditing: A Journal of Practice and Theory, v. 29, n. 1, pp. 73-97, 2010. https://doi.org/10.2308/aud.2010.29.1.73.

COELHO, C. M. P.; NIYAMA, J. K.; RODRIGUES, J. M. Análise da Qualidade da Informação Contábil Frente a Implementação dos IFRS: Uma Pesquisa Baseada nos Periódicos Internacionais (1999 a 2010). Sociedade, Contabilidade e Gestão, Rio de Janeiro, v. 6, n. 2, 2011. https://doi.org/10.21446/scg_ufrj.v6i2.13235.

COMISSÃO DE VALORES MOBILIÁRIOS. Instrução CVM 308 (ICMV 308). Dispõe sobre o registro e o exercício da atividade de auditoria independente no âmbito do mercado de valores mobiliários, define os deveres e as responsabilidades dos administradores das entidades auditadas no relacionamento com os auditores independentes. Disponível em: http://www.cvm.gov.br/legislacao/instrucoes/inst308.html. Acesso em: 09.04.2020.

COSENZA, J. P. Contabilidade criativa: as duas faces de uma mesma moeda. Pensar Contábil, v. 6. n. 20, mai-jul, p. 4-13, 2003. https://doi.org/10.21446/scg_ufrj.v6i2.13235.

CRABTREE, A. D. BRANDON, D. M.; MAHER, J. J. The impact of auditor tenure on initial bond ratings. Advances in Accounting, v. 22, pp. 97-121, 2006. https://doi.org/10.1016/S0882-6110(06)22005-4.

CHRISTENSEN, Hans B. et al. Incentives or standards: What determines accounting quality changes around IFRS adoption? European Accounting Review, v. 24, n. 1, p. 31-61, 2015. https://doi.org/10.1080/09638180.2015.1009144.

DANTAS, J. A.; MEDEIROS, O. R. Determinantes de Qualidade da Auditoria Independente em Bancos. Revista Contabilidade \& Finanças, USP, São Paulo, v. 26, no 67, p. 43-56, 2015. https://doi.org/10.1590/rcf.v26i67.98097.

DARROUGH, M.; RANGAN, S. Do Insiders Manipulate Earnings When They Sell Their Shares in an Initial Public Offering? Journal of Accounting Research, v. 43, n. 1, p. 1-33, 2005. https://www.jstor.org/stable/3542414.

DASKE, H.; HAIL, L.; LEUZ, C.; VERDI, R. Mandatory IFRS Reporting around the world: early evidence on the economic consequences. Journal of Accounting Research, v. 46, n. 5, p. 1085-1142, 2008. https://doi.org/10.1111/j.1475-679X.2008.00306.x.

DeANGELO, L. E. Auditor Size and Audit Quality. Journal of Accounting and Economics, v.3, p. 183-199, 1981. https://doi.org/10.1016/0165-4101(81)90002-1.

DECHOW, P.; Ge, W.; SCHRAND, C. Understanding earnings quality: A review of the proxies, their determinants and their consequences. Journal of Accounting and Economics, v. 50, p. 344-401, 2010. https://doi.org/10.1016/j.jacceco.2010.09.001.

DECHOW, P.; SKINNER, D. J. Earning management: reconciling the views of accounting academics, practitioners, and regulators. Accounting Horizons. v. 14, n. 2, 2000. https://doi.org/10.2308/acch.2000.14.2.235.

DeFOND, M. L.; LIM, C. Y.; ZANG, Y. Client Conservatism and Auditor-Client Contracting. Marshall Research Paper Series Working Paper ACC 01.16. USC Marshall School of Business. Forthcoming in The Accounting Review. 2015. SSRN. Recuperado em 23 de dez de 2016. https://ssrn.com/abstract=2601343.

DIAMOND, D. W.; VERRECCHIA, R. E. Disclosure, liquidity, and the cost of capital. The journal of finance, v. 46, n. 4, 1991. https://www.jstor.org/stable/2328861.

DUROCHER, S.; GENDRON, Y. IFRS: On the Docility of Sophisticated Users in Preserving the Ideal of Comparability. European Accounting Review, v. 20, n. 2, p. 233-262, 2011. Recuperado em 02 de abr de 2020. http://dx.doi.org/10.2139/ssrn.1322582

EWERT, R.; WAGENHOFER, A. Economic Effects of Tightening Accounting Standards to Restrict Earnings 
Management. The Accounting Review, v. 80, n. 4, p. 1101-1124, 2005.

FAFATAS, S. A. Auditor conservatism following audit failures. Managerial Auditing Journal, v. 25, no 7, p. 639-658, 2010. https://doi.org/10.1108/02686901011061333.

FAMA, E. F. Efficient capital markets: a review of theory and empirical work. Journal of Finance, v. 25, n. 2, p. 383-417, 1970. https://www.jstor.org/stable/2325486.

Financial Reporting Council (FRC). The audit quality framework. London. 2008. Disponível em: <https://www.frc.org.uk/getattachment/46582304-32b1-43bb-b614-90318b295f28/The-Audit-QualityFramework-Feb-2008.pdf >. Acesso em: 10.01.2017.

FLEMING, M. J. The round-the-clock market for U.S. treasury securities. FRBNY Economic Policy Review, v. 3, n. 2, 1997.

FRANCIS, J. R. A framework for understanding and researching audit quality. Auditing: A journal of Practice \& Theory, v. 30, n. 2, p. 125-152, 2011. https://doi.org/10.2308/ajpt-50006.

FRANCIS, J. R. The effect of audit firm size on audit prices. A Study of the Australian Market. The Journal of Accounting and Economics, v. 6, p. 133-151, 1984. https://doi.org/10.1016/0165-4101(84)90010-7.

FRANCIS, J. R. What do we know about audit quality? The British Accounting Review, v. 36, p. 345-368, 2004. https://doi.org/10.1016/j.bar.2004.09.003.

FRANCIS, J. R. MAYDEW, E. L.; SPARKS, H. C. The Role of Big 6 Auditors in the Credible Reporting of Accruals. Auditing: A Journal of Practice \& Theory, v. 18, n. 2, 1999.

https://doi.org/10.2308/aud.1999.18.2.17.

FRANCIS, J. R.; YU, M. D. Big 4 Office Size and Audit Quality. The Accounting Review, v. 84, n. 5, p. 1521-1552, 2009. https://doi.org/10.2308/accr.2009.84.5.1521.

FU, R.; KRAFT, A.; ZHANG, H. Financial reporting frequency, information asymmetry, and the cost of equity. Journal of Accounting and Economics, v. 54, p. 132-149, 2012.

https://doi.org/10.1016/j.jacceco.2012.07.003.

GAVIOUS, I. Alternative perspectives to deal with auditors' agency problem. Critical Perspectives on Accounting, v.18, p. 451-467, 2007. https://doi.org/10.1016/j.cpa.2006.01.011.

GENERAL ACCOUNTING OFFICE (GAO). Public Accounting Firms. Required Study on the Potential Effects of Mandatory Audit Firm Rotation. United States General Accounting Office, GAO-04-216, nov., 2003.

Disponível em: <https://www.gao.gov/new.items/d04216.pdf>. Acesso em: 15.06.2017.

GIRÃO, L. F. A. P.; MACHADO, M. R. A produção científica sobre assimetria informacional em periódicos internacionais de contabilidade. Revista de Contabilidade e Controladoria. Universidade Federal do Paraná, Curitiba, v. 5, n. 1, p. 99-119, 2013. http://dx.doi.org/10.5380/rcc.v5i1.29923.

HAO, J.; SUN, M.; YIN, J. Convergence to IFRS, accounting quality, and the role of regional institutions: evidence from China. Asian Review of Accounting, 2019. https://doi.org/10.1108/ARA-01-2017-0008

HASBROUCK, J. Empirical Market Microstructure: the institutions, economics, and econometrics of securities trading. Oxford University Press, Inc. 2007.

HEALY, P. M.; PALEPU, K. G. Information asymmetry, corporate disclosure, and the capital markets: A review of the empirical disclosure literature. Journal of Accounting and Economics, v. 31, p. 405-440, 2001. https://doi.org/10.1016/S0165-4101(01)00018-0.

HEALY, P. M.; WAHLEN, J. M. A Review of the Earnings Management Literature and Its Implications for Standard Setting. Accounting Horizons, v. 13, n. 4, p. 365-383, 1999.

https://doi.org/10.2308/acch.1999.13.4.365.

HU, D. Audit Quality and measurement: Towards a comprehensive understanding. Academy of

Accounting and Financial Studies Journal, v. 19, n. 1, 2015. Disponível em:

<https://www.researchgate.net/publication/281701417_Audit_quality_and_measurement_Towards_a_compr ehensive_understanding > Acesso em 15.06.2017.

IATRIDIS, G. International Financial Reporting Standards and the quality of financial statement information. International Review of Financial Analysis, v. 19, n. 3, p. 193-204, 2010.

https://doi.org/10.1016/j.irfa.2010.02.004.

INTERNATIONAL AUDITING AND ASSURANCE STANDARDS (IAASB). A Framework for Audit Quality.

Key elements that create an environment for Audit Quality. International Federation of Accountants

(IFAC). 2014. Disponível em: <https://www.ifac.org/system/files/publications/files/A-Framework-for-Audit- 
Quality-Key-Elements-that-Create-an-Environment-for-Audit-Quality-2.pdf>. Acesso em: 25.08.2017.

KIM, J.; LIU, X.; ZHENG, L. The impact of mandatory IFRS adoption on audit fees: Theory and evidence. The Accounting Review, v. 87, n. 6, p. 2061-2094, 2012. https://doi.org/10.2308/accr-50223.

KNECHEL, W. R. et al. Audit Quality: Insights from the Academic Literature. Auditing: A Journal of Practice \& Theory, v. 32, 2013. https://doi.org/10.2308/ajpt-50350.

$\mathrm{KOCH}, \mathrm{C}$.; WEBER, M.; WUSTEMANN, J. Can Auditors be Independent? Experimental Evidence on the Effects of Client Type. European Accounting Review, v. 21, n. 4, p. 797-823, 2012.

https://doi.org/10.1080/09638180.2011.629416.

LEIBLER, M. True and fair - an imaginary view. Australian Accounting Review, v. 13, n. 3. p. 61-66, 2003. https://doi.org/10.1111/j.1835-2561.2001.tb00172.x.

LEV, B. Toward a theory of equitable and efficient accounting policy. The Accounting Review. v. 63, n. 1, p. 1-22, 1988. https://www.jstor.org/stable/247676.

LYS, T.; WATTS, R. L. Lawsuits against Auditors. Journal of Accounting Research, v. 32, 1994. https://www.jstor.org/stable/2491440.

MARTÍNEZ-FERRERO, J.; VILLARÓN-PERAMATO, Ó.; GARCÍA-SÁNCHEZ, I. M. Can Investors Identify Managerial Discretion in Corporate Social Responsibility Practices? The Moderate Role of Investor Protection. Australian Accounting Review, v. 27, n. 1, p. 4-16, 2017. https://doi.org/10.1111/auar.12138.

MYERS, J. N.; MYERS, L. A.; SKINNER, D. J. Earnings Momentum and Earnings Management. Journal of Accounting, Auditing \& Finance, v. 22, n. 2, p. 249-284, 2007.

https://doi.org/10.1177/0148558X0702200211.

MYERS, J. N.; MYERS, L. A.; OMER, T. C. Exploring the Term of the Auditor-Client Relationship and the Quality of Earnings: A Case for Mandatory Auditor Rotation? The Accounting Review, v. 78, n. 3, p. 779799, 2003. https://doi.org/10.2308/accr.2003.78.3.779.

NG, P. P. H.; TAI, B. Y. K. An Empirical Examination Of The Determinants Of Audit Delay In Hong Kong. The British Accounting Review, v. 26, n.1, p. 43-59, 1994. https://doi.org/10.1006/bare.1994.1005.

NOBES, C.W. The continued survival of international differences under IFRS. Accounting and Business Research, v. 43, n. 2, p. 83-111, 2013. https://doi.org/10.1080/00014788.2013.770644.

PAULO, I. I. S. L de M.; CAVALCANTE, P. R. N.; PAULO, E. Relação entre qualidade da auditoria e conservadorismo contábil nas empresas brasileiras. REPEC - Revista de Educação e Pesquisa em Contabilidade, Brasília, v. 7, n. 3, p. 305-327, 2013. https://doi.org/10.17524/repec.v7i3.984.

PAULO, E.; CAVALCANTE, P. R. N.; MELO, I. I. S. L. Qualidade das informações contábeis na oferta pública de ações e debêntures pelas companhias abertas brasileiras, Brazilian Business Review, v. 9, n. 1, p. 1-26, 2012.

PIRES DA SILVA, J. et al. Convergência ao padrão IFRS e suavização de resultados em empresas de energia elétrica. Revista de Administração e Contabilidade da Unisinos, v. 14, n. 4, p. 821-296, 2017. DOI: https://doi.org/10.4013/base.2017.144.04.

REIS, E. M. dos; LAMOUNIER, W. M.; BRESSAN, V. G. F. Avoiding Reporting Losses: An Empirical Study of Earnings Management via Operating Decisions. Revista Contabilidade \& Finanças., USP, São Paulo, v. 26, n. 69, p. 247-260, set-dez, 2015. https://doi.org/10.1590/1808-057x201501070.

REZENDE, C. V. de; ALMEIDA, N. S. de; LEMES, S. Impacto das IFRS na assimetria de informação evidenciada no mercado de capitais brasileiro. Revista de Contabilidade e Organizações, n. 24, p. 19-30, 2015. https://doi.org/10.11606/rco.v9i24.55524.

RODRIGUES, S. DA S.; GALDI, F. C. Relações com investidores e assimetria informacional Revista Contabilidade \& Finanças. Universidade de São Paulo, USP, São Paulo, Brasil, v. 28. n. 74, p. 297-312, mai-ago, 2017. https://doi.org/10.1590/1808-057x201703630.

SALEHI, M.; MORADI, M.; PAIYDARMANESH, N. The Effect of Corporate Governance and Audit Quality on Disclosure Quality: Evidence from Tehran Stock Exchange. Periodica Polytechnica Social and Management Sciences, v. 25, p. 32-48, 2017. https://doi.org/10.3311/PPso.8354.

SALTER, S. B.; ROBERTS, C. B.; KANTOR, J. The IASC comparability project: A cross-national comparison of financial reporting practices and IASC proposed rules. Journal of International Accounting, Auditing and Taxation, v. 5, n. 1, p. 89-111, 1996. https://doi.org/10.1016/S1061-9518(96)90017-8.

SANTOS, L. P. G. et al. Efeito da Lei 11.638/07 sobre o conservadorismo condicional das empresas listadas 
BM\&FBOVESPA. Revista de Contabilidade e Finanças, USP, São Paulo, v. 22, n. 56, p. 174-188, 2011. https://doi.org/10.1590/S1519-70772011000200004.

SILBER, W. L. What happened to liquidity when world war I shut the NYSE? Journal of Financial Economics, v. 78, p. 685-701, 2005. https://doi.org/10.1016/j.jfineco.2005.02.005.

SIREGAR, S. V. et al. Audit Tenure, Auditor Rotation, and Audit Quality: The Case of Indonesia. Asian Journal of Business and Accounting, v. 5, n. 1, p. 55-74, 2012. Disponível em:

<https://ajba.um.edu.my/article/view/2653>. Acesso em: 16.06.2017.

SKINNER, D. J. Why firms voluntary disclose bad News. Journal of Accounting Research, v. 32, n. 1, p. 38-60, 1994. https://www.jstor.org/stable/2491386.

SMITH, L. M. Audit committee effectiveness: did the blue ribbon committee recommendations make a difference? Int. J. Accounting, Auditing and Performance Evaluation, v. 3, n. 2, 2006.

DOI: 10.1504/IJAAPE.2006.010303.

SOLOMON, I.; SHIELDS, M. D.; WHITTINGTON, O. R. What Do Industry-Specialist Auditors Know? Journal of Accounting Research, v. 37, n. 1, p. 191-208, 1999.

https://doi.org/10.1016/j.jaccpubpol.2010.10.002.

SUN, J.; LIU, G. Industry specialist auditors, outsider directors, and financial analysts. Journal of Accounting and Public Policy, v.30, n. 4, p. 367-382, 2011.

https://doi.org/10.1016/j.jaccpubpol.2010.10.002.

VERRECCHIA, R. E. Essays on disclosure. Journal of Accounting and Economics, v. 32, p. 97-180, 2001. https://doi.org/10.1016/S0165-4101(01)00025-8.

WELKER, M. Disclosure policy, information asymmetry and liquidity in equity Markets. Contemporary accounting research, v. 11, n. 2. p. 801-827, 1995. https://doi.org/10.1111/j.1911-3846.1995.tb00467.x.

WITTENBERG-MOERMAN, $R$. The role of information asymmetry and financial reporting quality in debt trading: Evidence from the secondary loan market. Journal of Accounting and Economics, v. 46. p. 240260, 2008. https://doi.org/10.1016/j.jacceco.2008.08.001.

WOOLDRIGE, J. M. (2012). Introductory Econometrics. A modern Approach. 5th Edition. SouthWestern.

YIP, R. W.; YOUNG, D. Does mandatory IFRS adoption improve information comparability? The Accounting Review, v. 87, n. 5, p. 1767-1789, 2012. https://doi.org/10.2308/accr-50192.

ZEFF, Stephen A. Some obstacles to global financial reporting comparability and convergence at a high level of quality. The British Accounting Review, 39, 2007, p. 290-302. DOI:

https://doi.org/10.1016/j.bar.2007.08.001.

ZHANG, Y., ANDREW, J. Land in China: Re-considering comparability in financial reporting. Australian Accounting, Business and Finance Journal, v. 4, n. 1, p. 53-75, 2010.

\section{NOTAS}

\section{AGRADECIMENTOS}

Os autores agradecem as contribuições dos pareceristas do XII Congresso da Anpcont e da Revista Contemporânea de Contabilidade, que possibilitaram uma série de melhorias ao artigo. Naturalmente, os erros eventualmente cometidos são de exclusiva responsabilidade dos autores.

\section{CONTRIBUIÇÃO DE AUTORIA}

Concepção e elaboração do manuscrito: T. Arcúrio Jr., R. de S. Gonçalves

Coleta de dados: T. Arcúrio Jr.

Análise de dados: T. Arcúrio Jr., R. de S. Gonçalves

Discussão dos resultados: T. Arcúrio Jr., R. de S. Gonçalves

Revisão e aprovação: T. Arcúrio Jr., R. de S. Gonçalves

\section{CONJUNTO DE DADOS DE PESQUISA}

O conjunto de dados que dá suporte aos resultados deste estudo não está disponível publicamente.

\section{FINANCIAMENTO}

Não se aplica.

\section{CONSENTIMENTO DE USO DE IMAGEM}

Não se aplica. 


\section{APROVAÇÃO DE COMITÊ DE ÉTICA EM PESQUISA}

Não se aplica.

\section{CONFLITO DE INTERESSES}

Não se aplica.

\section{LICENÇA DE USO}

Os Direitos Autorais para artigos publicados neste periódico são do autor, com direitos de primeira publicação para a Revista. Em virtude de aparecerem nesta Revista de acesso público, os artigos são de uso gratuito, com atribuições próprias, em aplicações educacionais, de exercício profissional e para gestão pública. A Revista adotou a licença Creative Commons Atribuição 4.0 Internacional - CC BY NC ND. Esta licença permite acessar, baixar (download), copiar, imprimir, compartilhar, reutilizar e distribuir os artigos desde que com a citação da fonte, atribuindo os devidos créditos de autoria. Nesses casos, nenhuma permissão é necessária por parte dos autores ou dos editores. Autores têm autorização para assumir contratos adicionais separadamente, para distribuição não-exclusiva da versão do trabalho publicada nesta revista (ex.: publicar em repositório institucional ou um capítulo de livro).

\section{PUBLISHER}

Universidade Federal de Santa Catarina. Curso de Ciências Contábeis e Programa de Pós-graduação em Contabilidade. Publicação no Portal de Periódicos UFSC. As ideias expressadas neste artigo são de responsabilidade de seus autores, não representando, necessariamente, a opinião dos editores ou da universidade.

\section{EDITORES}

Carlos Eduardo Facin Lavarda e Suliani Rover

\section{HISTÓRICO}

Recebido em: 30/07/2018 - Revisado por pares em: 23/03/2020 - Reformulado em: 11/04/2020 Recomendado para publicação em: 02/05/2020 - Publicado em: 30/05/2020

Uma versão preprint do artigo foi apresentada no XII Congresso Anpcont, João Pessoa, 2018. 